\title{
Developing a Water Quality Assessment Framework for Southwest Florida Tidal Creeks
}

\author{
Michael R. Wessel ${ }^{1}$. Jay R. Leverone ${ }^{2} \cdot$ Marcus W. Beck $^{3}$ - Edward T. Sherwood ${ }^{3}$. Jennifer Hecker ${ }^{4} \cdot$ Steven West $^{1}$. \\ Anthony Janicki ${ }^{1}$
}

Received: 20 August 2020 / Revised: 26 April 2021 / Accepted: 10 June 2021 / Published online: 4 July 2021

(c) The Author(s) 2021

\begin{abstract}
The three contiguous National Estuary Programs of southwest Florida, along with partners from six coastal counties, have developed a tidal creek water quality assessment framework to help prioritize natural resource investigations across a large population of tidal creeks between Tampa Bay and Estero Bay, Florida. The assessment framework is based on outcomes of a multidisciplinary study and includes a nutrient based report card that characterizes nutrient conditions relative to regional numeric nutrient criteria developed for contributing freshwater streams, identification of site-specific water quality indicators of tidal creek condition, and an online open science dashboard to display the assessment framework and provide access to all information relevant to its implementation. Application of the assessment framework has provided an actionable list of southwest Florida tidal creeks prioritized for further research and potential management action along with a host of sitespecific indicator results that provide insights into drivers of tidal creek condition. The open science dashboard provides a platform for dissemination of this information in a readily accessible and reproducible format and a means to incorporate new data and indicators as they become available. Local resource managers are in need of tools to help prioritize natural resource investigations and management actions that achieve the greatest resource benefit with limited available resources. This assessment framework informs these efforts and builds capacity for future research to identify and refine management tools for these creeks where management resources, data, and sentinel biological response endpoints are limited.
\end{abstract}

Keyword Tidal Creek · Nutrient · Management Framework

\section{Introduction}

Tidal creeks are abundant in estuarine ecosystems, particularly in the low-energy coastal areas of the southeastern USA, yet their ecological relevance remains undervalued compared to larger, better-known estuarine systems (Mallin and

Communicated by Hans W. Paerl.

Michael R. Wessel

mwessel@janickienvironmental.com

1 Janicki Environmental, Inc, 1155 Eden Isle Dr., St. Petersburg, FL 33704, USA

2 Sarasota Bay Estuary Program, 111 S Orange Ave \#200w, Sarasota, FL 34236, USA

3 Tampa Bay Estuary Program, 263 13th Ave S, St. Petersburg, FL 33701, USA

4 Coastal \& Heartland National Estuary Partnership, 326 W. Marion Ave, Punta Gorda, FL 33950-4417, USA
Lewitus 2004). Tidal creeks provide critical habitat for many important estuarine dependent nekton species as a complementary ecotone to the larger estuary (Mallin et al. 2004; Holland et al. 2004; Greenwood et al. 2008; Krebs et al. 2010; Sherwood 2010) and their collective importance in material transfer and other ecological processes may equal or exceed that of larger estuaries (Dame et al. 2000; Mallin et al. 2004). The introduction of excess nutrients to coastal systems is a leading cause of observed water quality problems (Nixon 1995; National Research Council 2000; Crain 2007; Gilbert et al. 2010), and tidal creeks are critical pathways for nutrients between the landscape and the estuary. Tidal creeks receive and deliver nutrients from both anthropogenic sources (Mallin et al. 1999, 2004; Mallin and Lewitus 2004; Holland et al. 2004; Sanger et al. 2015) and via decomposition of natural sources (Cloern 2001; Castro et al. 2003; Wolanski 2007; Deinenger and Frigstad 2019). The differences between these sources are important for management, yet tidal creeks remain understudied. 
In Florida, tidal creeks tend to be locally underrepresented in ambient water quality and environmental monitoring programs. This is due in part to difficulties in accessing what are often small tributaries surrounded by private lands or inaccessible floodplain areas. In addition, resource managers have tended to concentrate efforts on characterizing water quality delivered to the tidal portion of the system to estimate nutrient loads to the estuary rather than characterizing nutrient inputs and processes within the tidal portion of these creeks. Consequently, management and regulatory efforts to protect Florida's tidal creeks have lagged behind other waterbody types governed by the Clean Water Act. Southwest Florida includes several hundred tidal creeks that are not currently protected by defined numeric nutrient criteria but drain into prominent "estuaries of national significance" including Tampa Bay, Sarasota Bay, and Charlotte Harbor, many of which have overlapping designations as Outstanding Florida Waters or are within expansive state aquatic preserves. While numeric nutrient criteria have been developed for Florida springs, lakes, freshwater streams, and estuaries, tidal tributaries (including rivers and creeks) remain governed by a narrative criterion to protect waters from "an imbalance of flora and fauna" as defined in Florida Administrative Code (Rule 62-302.530(48)(b) F.A.C.) unless site-specific criteria have been established. Evaluation of the narrative criterion is based on chlorophyll $a$ and dissolved oxygen standards developed principally for open bay estuaries. When violations of these numeric interpretations of the narrative criterion occur, nutrients are inferred as the causative pollutant. Local resource managers would benefit from water quality standards and numeric nutrient criteria developed using data collected within tidal creeks.

The need to develop a management strategy for southwest Florida tidal creeks was first promoted by the Tampa Bay Regional Planning Council in 1986 (Clark 1987; Clark 1991). Since that time, several important studies have been conducted on the value, function, and drivers of ecological integrity of southwest Florida tidal tributaries, including both larger tidal river systems and smaller tidal creeks. Sherwood (2008) and collaborators conducted a mutlidisciplinary tidal tributary habitat initiative in Tampa Bay, Florida, and concluded among other things that benthic microalgae were the primary source of food for fishes in tidal tributaries and that flashy stormwater runoff to tidal tributaries from more developed watersheds threatens benthic microalgae production by reducing water quality and light availability to benthic habitats. Burghart et al. (2013) used multivariate analyses of zooplankton community structure to develop breakpoints in the ratio of pelagic and demersal species composition as indicators of eutrophication based on sampling 4 spring fed and 4 surface water fed tidal rivers in southwest Florida. Peebles (2015) used zooplankton and hyperbenthos community metrics to develop indictors of trophic state for 6 tidal creeks in Tampa Bay, Florida, and found standard community diversity metrics (e.g. Shannon Weiner, Pielou's Evenness) may serve as valuable indicators of tidal creek trophic state. These studies, as well as several others (Krebs et. al. 2007; Yeager et. al. 2007; Greenwood et. al. 2008; Sherwood 2010; Malkin et. al. 2010; Barbour and Adams 2012; Ley and Rolls 2018), were synoptic surveys designed to assess tidal creek conditions beneficial for estuarine dependent and resident fish, zooplankton, or hyperbenthos communities as biological response endpoints. These studies have contributed substantially to the identification of potential biological response endpoints for these systems as well as identifying drivers related to their success. However, these studies were not directly focused on identifying nutrient concentrations that could be used to list and prioritize creeks for management actions and gaps remain in defining the linkage between water column nutrient concentrations and biological response endpoints in a manner that can be used to develop discrete numeric water quality thresholds indicative of degradation of these systems. The three southwest Florida National Estuary Programs (NEPs) and their partners were interested in expanding research on southwest Florida tidal creeks to fulfill their own conservation and management objectives with respect to their proper stewardship and with the hope that this information may be used to inform future numerically based nutrient criteria for these systems.

This paper describes the development of a tidal creek water quality assessment framework to evaluate tidal creek condition across a large study area using a set of metrics derived from commonly collected water quality data. The goal of the effort was to coordinate and accelerate stewardship of more than 300 tidal creeks between Tampa Bay and Estero Bay in southwest Florida. Our assessment framework does not have any regulatory implications. Rather, the framework is designed to provide an openly available and continually updated assessment of tidal creek water quality condition that resource managers can use to screen and prioritize tidal creeks for nutrient management initiatives and/ or future research. We collected water quality and biological response endpoint data for a subset of creeks across a large study area, evaluated those data to identify water quality indicators and potential thresholds related to creek condition, and then applied the thresholds and indicators as an assessment framework to the identified population of creeks in southwest Florida using a large state and federal water quality repository. The objectives of using the assessment framework were to (1) report on tidal creek water quality conditions across a large population of tidal creeks between Tampa Bay and Estero Bay, Florida, (2) complement existing narrative-based regulatory standards for nutrients by providing additional context on site-specific creek conditions that may affect observed outcomes from current regulatory 
evaluations, and (3) prioritize investigations and potential management actions across the population of tidal creeks. The study involved identifying the population of creeks, conducting analyses of field data collections to develop a report card and indicator metrics, applying and testing metrics using a large long-term regulatory water quality database, and implementing the assessment tools with open source software in an online, interactive dashboard to directly support proactive local environmental management actions for southwest Florida tidal creeks.

\section{Methods}

\section{Data Collection}

The study area encompassed the watershed boundaries of the three southwest Florida NEPs between Tampa Bay and Estero Bay, Florida (Fig. 1). The National Hydrography Datasets (i.e., NHD-Plus; McKay et al. 2012), at 1:24 K and 1:100 K scales, were used in Geographic Information System (GIS) to identify the potential population of tidal creeks within the study area. Meetings were held with project partners to review the hydrography dataset, gather local knowledge on the creek population, and identify inclusion criteria which we defined as any natural or physically altered system (typically Strahler (1952) 3rd order or less) receiving freshwater inputs and exhibiting a range in salinities during a typical hydrologic year. The $1: 100 \mathrm{~K}$ scale was initially chosen for identifying the population, which was then supplemented by additional creeks at the 1:24 K scale based on local knowledge and expertise of project partners. For instance, a small 2nd-order river (Estero River) was included in the population since its watershed area and creek length were smaller than other tributaries identified as "creeks" in the study area. We use the term "tidal creeks" to differentiate these systems from larger tributaries (i.e. higher order rivers) within the study area. The final identified population of 306 tidal creeks for this study is shown as black lines in Fig. 1. The tidal boundary (shading in Fig. 1) was defined using the Florida Department of Environmental Protection's (FDEP) Marine Water Body Identification Number (WBID) and FDEP saltwater interface boundaries along with a $1.66-\mathrm{km}$ (1 mile) buffer which defined the landward most perimeter of the tidal portion of the creek.

Southwest Florida tidal creeks range from relatively natural systems to heavily modified ditches and urban stormwater conveyances, and a classification scheme was developed to balance the sampling effort across a range of potential conditions. First, a matrix of watershed attributes was developed that included (1) existing information on hydrologic soil groups and soil phosphorus concentrations (U.S. Department of Agriculture (USDA), Natural Resources Conservation Service (NRCS), National Soil Survey Handbook, n.d.)),

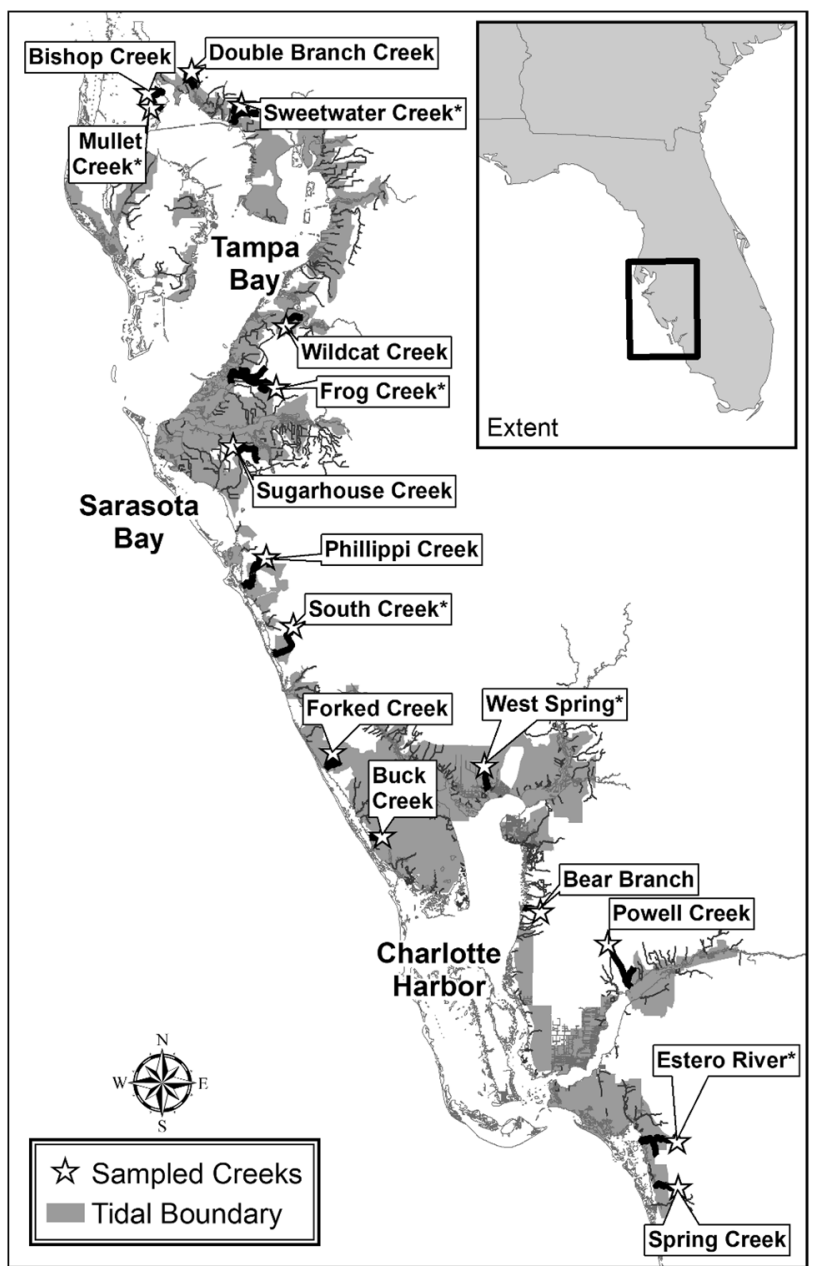

Fig. 1 Geographic boundaries of the study area for defining the population of tidal creeks with the 16 sampled creeks bolded and labeled

(2) a landscape development index (LDI: Brown and Vivas 2005) for the creekshed and for a 50-m buffer from the creek centerline, (3) the percent of the creekshed that was classified as impervious surface based on the 2011 National Land Cover Database classification scheme (Wickham 2020), (4) elevation change within the tidal portion of the creek based on Digital Elevation Model data, (5) estimated nutrient loadings from previous NEP watershed loading models, and (6) several other metrics characterizing landscape attributes to further refine a classification scheme. Hierarchical agglomerative clustering was used to develop a cluster dendogram based on a resemblance matrix of watershed attributes and simple matching using normalized data values (Clarke and Gorley 2006). Three principal categories were separated at a cutoff value of $60 \%$ similarity (Class B, C, and D). To limit the size of the smallest class, the creeks with the lowest group average similarity relative to the three other classes were combined into a single additional class (A) and 16 
creeks were selected (4 from each class) for sampling. Class A creeks tended to be the longest creeks with the highest nutrient loadings, class B creeks tended to have the highest proportion of type A soils and the highest LDI scores, class $\mathrm{C}$ creeks tended to have the lowest LDI scores and the highest proportion of USDA NRCS B soils, and class D creeks tended to have the lowest soil $\mathrm{P}$ concentrations, but otherwise appeared to be similar to either B or C classes depending upon which watershed characteristic was compared. These classes were merely used to distribute our sampling across the range of watershed attribute and were not directly used to develop the assessment framework.

Two sampling surveys were conducted to collect data on water column nutrients, chlorophyll $a$, physical chemistry, and biological response endpoints in southwest Florida tidal creeks. Water quality analytes included constituents commonly collected in routine water quality monitoring programs while biological response endpoints included those identified in previous regional studies mentioned above. First, 16 creeks (labeled as bold lines in Fig. 1) were sampled every other month between November 2013 and September 2014. This survey (Janicki Environmental and Mote 2016) was designed to obtain unbiased estimates of the annual geometric mean nutrient concentrations relevant to typical Florida regulatory assessments, while also evaluating instream nutrient dynamics and biological response endpoints including benthic chlorophyll a content and nekton (fish) communities utilizing the creeks. The chlorophyll content of the top $1 \mathrm{~cm}$ of the creek bed (i.e. benthic chlorophyll $a$ ) was sampled using a $60-\mathrm{cm}^{3}$ syringe as a core based on outcomes of Sherwood (2008). The sample was collected either as a sub-sample of a petite ponar grab of the sediment or, if water levels were shallow enough, directly from the creek bed. Five replicate samples were collected at evenly spaced intervals along the left and right bank of the creek at the same randomly generated sampling point where water quality and fish samples were collected. Samples for each bank were then composited into a single sample for analysis. Benthic chlorophyll $a$ content was determined using the modified fluorometric method of Whitney and Darley (1979) and Pinkney et al., (1994). Fish were collected according to Sherwood (2008) and others using a 9.1-m (3 mm mesh) raft seine $(1.2 \mathrm{~m}$ high with a $1.2-\mathrm{m} \times 0.9-\mathrm{m} \times 0.9-\mathrm{m}$ bag placed in the center) along the shoreline in depths $1.0 \mathrm{~m}$ or less to evaluate fish community structure. All species were identified to the lowest taxonomic level, measured in standard length, and enumerated.

For the second study (Janicki Environmental and Mote 2019), 6 of the previously selected 16 creeks (creeks with asterisk in Fig. 1) were chosen for sampling by our County partners (a single creek within each county) in consultation with the project team and sampled monthly during Spring and Fall months for 2 years beginning in April 2017. Benthic chlorophyll $a$ and fish sampling was omitted from the second survey to focus on water quality dynamics over multiple years in a consensus-based decision with project partners given the fixed allocation of effort and results of the previous survey. The spring and fall seasons were chosen to bracket the traditional summer wet season when ca. $60 \%$ of the annual rainfall occurs in SW Florida and because nutrient transformations and phytoplankton uptake were observed to be most dynamic within the system during this time based on outcomes from the first study.

Both surveys collected data to evaluate water quality dynamics within the creek from the upstream extent of the creek's tidal segment to near the mouth of the creek by sampling four locations along the length of the creek. For each event, a fixed station located just upstream of the anticipated tidal head, and three sites located within three $200 \mathrm{~m}$ strata located along the length of the tidal segment were sampled (Fig. 2). The strata were not necessarily contiguous based on the length of the tidal portion of the creek. For the first survey, probabilistic site selection was used within the three tidal strata while for the second survey; a fixed site was established within each of the three strata at the center point. Sites were accessed either by small boat or by wading, dependent upon access to the location and depth of the creek. All creeks were sampled within a two-day window across the study area for each event and all samples were conducted during daylight hours, typically prior to noon and irrespective of tidal stage as the area exhibits a mixed semidiurnal tidal pattern (McPherson and Hammett 1991). All water quality samples were conducted in accordance with FDEP standard operating procedures (http://www.dep.state. fl.us/water/sas/sop/sops.htm). Although the analytical methods defining the water quality constituents varied slightly between the two surveys (laboratory analysis for the second study included dissolved fractions and oceanographic methods with lower detection limits), analytical chemistry for both surveys was performed by the same NELAC certified laboratory, compared for reliability, and approved as part of a USEPA Quality Assurance Project Plan. Detailed information on analytical methods can be found in the supplementary materials for this paper (Tables S1 and S2).

\section{Data Analysis}

The field data were analyzed to assess potential stressorresponse relationships between nutrient concentrations and water quality and biological response endpoints that could be used to identify potential unifying numeric nutrient thresholds to protect tidal creek integrity. Data analysis methods included general linear models with tests for influence of random intercepts and residual correlation among samples collected within creek by date using Akaike Information Criteria for small sample size (AICC: 
Fig. 2 Generalized sampling scheme for 16 creeks sampled between November 2013 and December 2018

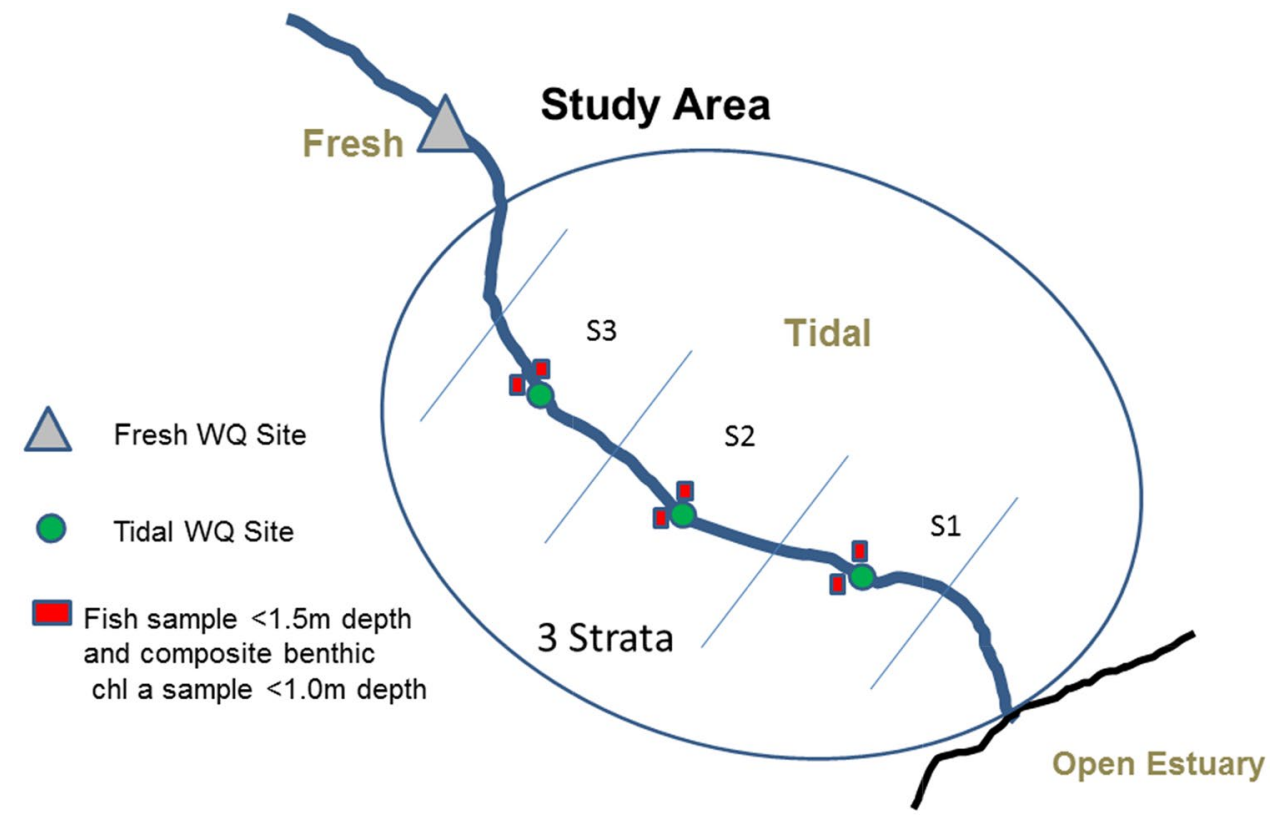

Littell et al. 2006), analysis of variance with Tukey post hoc multiple comparison adjustment for fish catch statistics, robust regression (Rousseeuw and Leroy 2003), and Monte Carlo simulation (Davidson and Hinkley 2003) implemented using SAS software (SAS Institute, Inc. 2019). In addition, conditional probability analysis was conducted using classification and regression trees (Rokach and Maimon 2008) for exploratory data analysis and indicator development and implemented in $\mathrm{R}$ ( $\mathrm{R}$ Core Team 2020). Specifically, conditional inference trees and ensemble models were implemented using the PARTY (Hothorn et al. 2006) and RandomForest (Breiman 2001) packages, respectively. These tools provide a flexible approach to evaluate nonlinear or threshold responses and can provide insight on conditional relationships among a host of potential explanatory drivers. Potential predictors included a host of landscape attributes including impervious surface, landscape development intensity index, natural buffer area, land use type, etc. (Table S3), as well as collected instream nutrient and physical chemistry water quality data. The response measures analyzed for this paper included water column and benthic chlorophyll $a$, dissolved oxygen, and fish/benthos community descriptors indicative of potential adverse impacts from nutrient pollution. The Standardized Precipitation Index was calculated using the SPEI package in R (Vincente-Serrano 2010) to evaluate the sampling effort relative to rainfall anomalies and assess potential relationships between rainfall anomalies and water quality.

\section{Report Card and Indicator Development}

Data from our field surveys were also used to inform development of a water quality "Report Card" and "Indicators" of tidal creek condition and these tools were then applied to the entire population of tidal creeks using data from the Florida statewide regulatory Watershed Information Network (WIN) database. The report card was derived as a screening tool to characterize creeks based on concentrations of the limiting nutrient (i.e. nitrogen) in the system. The report card utilized a "reference condition" approach with the reference being the established numeric nutrient criteria for the contributing freshwater stream. The current regulatory standards for total nitrogen in contributing freshwater streams in our study area are based on annual geometric means (AGMs) of $1.65 \mathrm{mg} / \mathrm{l}$ for the West Central region which includes Hillsborough, Manatee, Sarasota, and Charlotte Counties, and $1.54 \mathrm{mg} / \mathrm{l}$ for the Peninsula region which includes Pinellas and Lee counties. A 5-level classification scheme was developed based on these reference values and each year of data was categorized into one of 5 levels ("Prioritize," "Investigate," "Caution," "Monitor," "No Data"). A 10 year period analogous to Florida's water quality assessment "planning period" was evaluated and each year was assigned category. Creeks exceeding the freshwater numeric thresholds were assigned the "Prioritize" level. A proactive margin of safety was used to define the "Investigate" level category using Monte Carlo simulation and the standard deviation based on the pooled data from our first study. The simulation process used the 
expected value and standard deviation of log transformed observed data to derive a large simulated data pool $(10,000$ observations). Assuming six sampling events per year, a distribution of AGMs was generated based on 1000 replicates and the number of AGMs exceeding the regulatory threshold was calculated. The expected value was then incrementally shifted until a distribution with a 5\% probability of exceeding the regulatory threshold for the contributing freshwater portion of the creek was identified. The expected value of that distribution was then chosen as a threshold AGM value for the Investigate level category.

The Prioritize and Investigate levels are regionally based and proactively identify creeks that may be approaching impaired status for further study and potential management action. However, an additional goal of this study was to provide guidance for proper stewardship of individual creeks that may require more site-specific nutrient management strategies. As such, a "Caution" category was developed to identify creeks where nutrient concentrations were considered elevated given site-specific conditions. Preliminary analyses demonstrated that several creek watershed attributes were correlated with the AGM concentrations for total nitrogen and total phosphorus, including creek length, watershed size, buffer acreage, area of natural wetland vegetation (predominantly mangroves) within tidal reaches, and the AGM concentration of colored dissolved organic matter. A simple linear regression relationship between nitrogen concentration and the estuarine total creek length (Table S4) was chosen as a scaling factor for defining the lower limit of the Caution category, due to its broad applicability for all creeks whether or not water quality data or other watershed attributes were readily available. The Caution level was constructed to protect smaller creeks from elevated nutrient concentrations as a stewardship goal. Finally, a "Monitor" category was designated for any creeks with existing data that fell below the Caution level criterion value, and a "No Data" category was assigned to those creeks where data were unavailable for evaluation.

A scoring algorithm was derived to define the final report card outcome for each creek using the entire ten year record of available data based on the following criteria. A single exceedance of the Prioritize and Investigate categories in any year of the ten year record would result in a classification of that creek into the respective category unless at least three other years of data were below the threshold level for that category. Creeks were assigned the next lower category if only one AGM for total nitrogen (TN) was above a given level while multiple other years (i.e., more than two) were below the given levels defining the cutoff points for each category. For example, a creek with at least 4 years of data and only a single exceedance of the Prioritize threshold would be assigned the Investigate category. The WIN database includes assigned waterbody identifiers (WBIDs) intended to represent discrete hydrologic units. Since it was possible for multiple WBIDs to exist within the tidal portion of the creek, the report card evaluation was carried out by WBID. In rare cases where multiple WBIDs exist within the tidal creek, the creek was assigned the highest observed category for the report card display. A schematic representation of the data synthesis process is provided in Fig. 3 where the raw data timeseries is provided (Fig. 3a); each year's data is assessed relative to the categories (Fig. 3b). The 10 years of data are summarized by the frequency counts in each category (Fig. 3c) and the final report card outcome score is derived (Fig. 3d).

Water quality Indicators were developed based on outcomes of our study as described in detail in the results section. The results for each indicator were calculated on an annual basis and then synthesized for the 10-year period by calculating the percentage of annual outcomes above the identified threshold indicator values out of the total number of years with available data. An integrative summary for all indicators was presented using a standardized polar coordinate system and radar charts to provide a single multimetric summary plot of the results across indicators.

\section{Tidal Creeks Dashboard}

An online, interactive dashboard was created for the assessment framework to help automate and distribute summary information on tidal creek condition to regional environmental managers. The dashboard is also freely available for the general public to better understand the importance of tidal creeks as environmental resources that support healthy estuarine ecosystems. All dashboard components were created using the open source R Statistical Programming Language (R Core Team 2020). Specifically, the R Shiny package (Chang et al. 2020) was used to create the interactive web interface and the "tbeptools" R package (Beck et al. 2021) created by the authors was used to read, analyze, and graph data for the tidal creek indicators.

\section{Results}

\section{Study Results}

A total of 672 water quality samples were collected between the two studies (Table 1). TN concentrations ranged from 0.41 to $2.32 \mathrm{mg} / \mathrm{l}$. Total phosphorus (TP) ranged from 0.02 to $3.19 \mathrm{mg} / \mathrm{l}$. Corrected chlorophyll $a$ (Chla) concentrations ranged from 0.37 to $229.0 \mu \mathrm{g} / \mathrm{l}$ and were highly variable. Episodic spikes over $100 \mu \mathrm{g} / \mathrm{l}$ were observed in the tidal portion of the creek, though average concentrations were 
(a) Raw nitrogen data

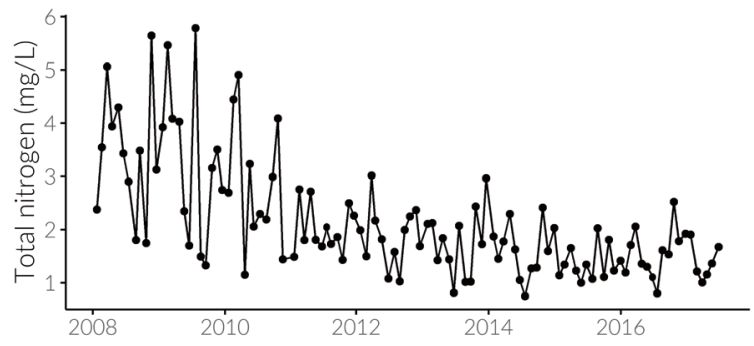

(c) Score categories for each year
2008200920102011201220132014201520162017

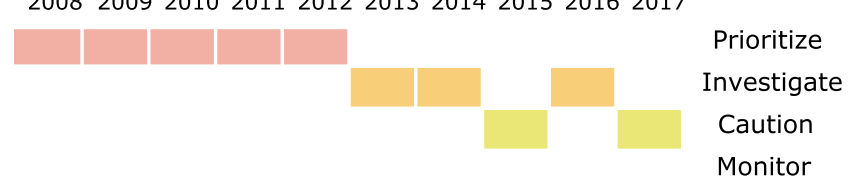

(b) Annual geometric means and thresholds for score summaries

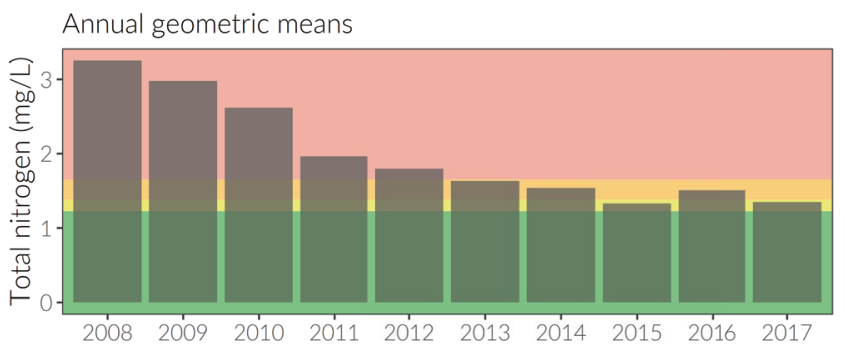

(d) Total counts and the final score category

No data

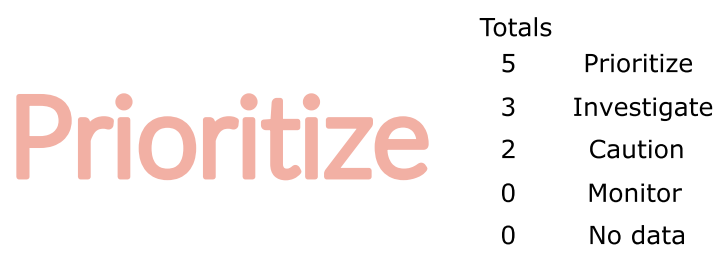

Fig. 3 Example schematic of using the report card to assign a creek into one of five management categories. Raw nitrogen data (a) are summarized by annual geometric means (b). Each year of data is then categorized into one of five management categories (c) and an overall outcome for the complete time series is assigned (d)

example of the dynamic nature of instream tidal creek water quality dynamics from our study is provided in Fig. 4 for samples collected in the spring of 2017 in Estero River. A high antecedent rainfall condition $(31.5 \mathrm{~cm}$ of rain in the 14 days prior to a June 2017 sampling event resulted in water quality with near zero psu salinities throughout the sampling area (4a), high color concentrations throughout the tidal portion of the creek (4b), relatively high $\mathrm{TN}$ throughout the tidal portion of the creek (4c), and low Chla, as residence times were presumably insufficient for phytoplankton production (4d). Alternatively, the April and May 2017 sampling events, with $0.5 \mathrm{~cm}$ and $4.3 \mathrm{~cm}$ of rain in the 14 days prior to sampling, respectively, exhibited more typical dry season conditions. During the dry season, a strong salinity gradient, lower color, lower TN, and higher overall Chla concentrations were observed in the tidal portion of the stream. Interestingly, the highest Chla concentrations were associated with some antecedent rainfall but not enough to have a marked effect on reducing salinity. These events all occurred at or near high slack tide with consistent depths of between 1.2 and $1.6 \mathrm{~m}$.

Bivariate stressor-response relationships between nutrients and water quality response endpoints were observed when grouping all data among creeks, though standard linear regression model fit was poor (Fig. 5). Significant $(\alpha=0.05)$ positive relationships were observed between Chla and both TN and TP (Fig. 5a, b). Dissolved oxygen was negatively related to TN concentrations (Fig. 5c). These results conform to expectations under the current management ent rainfall conditions throughout the year. A representative 
Table 1 Descriptive statistics for principal water quality constituents collected in 16 southwest Florida tidal creeks sampled between November 2013 and December 2018. Values shown are averages with

\begin{tabular}{|c|c|c|c|c|c|c|c|c|}
\hline Creek & Portion & Count & $\mathrm{TN}(\mathrm{mg} / \mathrm{l})$ & $\mathrm{TP}(\mathrm{mg} / \mathrm{l})$ & Chl-a $(\mu \mathrm{g} / \mathrm{l})$ & Salinity (psu) & DO (mg/l) & Turbidity (ntu) \\
\hline \multirow[t]{2}{*}{ Bear } & $\mathrm{Ti}$ & 18 & $0.9(0.6,1.3)$ & $0.1(0.1,0.2)$ & $14(1.7,34)$ & $20.6(3.9,30.3)$ & $2.2(0.8,4.8)$ & $9.0(1.1,28)$ \\
\hline & $\mathrm{Fr}$ & 6 & $0.8(0.4,1.3)$ & $0.1(0,0.2)$ & $6.3(0.6,16.5)$ & $0.3(0.2,0.3)$ & $7.9(4.6,10.2)$ & $7.1(1.9,15)$ \\
\hline \multirow[t]{2}{*}{ Bishop } & $\mathrm{Ti}$ & 18 & $0.8(0.5,1.1)$ & $0.2(0.1,0.3)$ & $4.9(0.6,12.7)$ & $8.5(0.2,22.2)$ & $5.9(1.4,12.5)$ & $4.5(3.8,6.1)$ \\
\hline & $\mathrm{Fe}$ & 6 & $0.7(0.6,0.9)$ & $0.2(0.1,0.3)$ & $3.2(0.9,8.8)$ & $0.3(0.2,0.5)$ & $6.1(4.7,8.2)$ & $7.5(1.6,22)$ \\
\hline \multirow[t]{2}{*}{ Buck } & $\mathrm{Ti}$ & 18 & $1(0.8,1.8)$ & $0.1(0.1,0.2)$ & $16.9(8.2,32.1)$ & $16.1(2,31.6)$ & $4.2(0.5,10.4)$ & $3.9(1.6,8.7)$ \\
\hline & Fr & 6 & $1.3(1.1,1.5)$ & $0.1(0.1,0.1)$ & $7.7(3,15.1)$ & $1.1(0.2,3.9)$ & $5.6(4.3,7.4)$ & $8.8(3.4,22)$ \\
\hline \multirow[t]{2}{*}{ Double branch } & $\mathrm{Ti}$ & 18 & $1.1(0.8,1.4)$ & $0.1(0.1,0.2)$ & $8.6(2.4,28.7)$ & $4.3(0.2,20.5)$ & $6(4,9.7)$ & $7.6(2.8,29)$ \\
\hline & $\mathrm{Fr}$ & 6 & $1(0.7,1.6)$ & $0.1(0.1,0.2)$ & $5(1.4,13.7)$ & $0.1(0.1,0.2)$ & $7(6,9.4)$ & $4.5(3.2,5.8)$ \\
\hline \multirow[t]{2}{*}{ Estero } & $\mathrm{Ti}$ & 54 & $0.9(0.6,1.6)$ & $0.1(0,0.2)$ & $18.5(1,228.5)$ & $10.3(0.2,25.4)$ & $3.6(1,10.7)$ & $11.7(3.3,35)$ \\
\hline & Fr & 18 & $0.9(0.6,1.3)$ & $0.1(0,0.1)$ & $12.2(1.9,53)$ & $0.3(0,0.3)$ & $4.7(1.8,8)$ & $3.2(1.4,9.6)$ \\
\hline \multirow[t]{2}{*}{ Forked } & $\mathrm{Ti}$ & 18 & $0.8(0.7,1)$ & $0.3(0.2,0.4)$ & $14.4(6,22.6)$ & $25.9(15.6,30.3)$ & $5.7(2.4,11)$ & $3.7(2.7,5.9)$ \\
\hline & $\mathrm{Fr}$ & 6 & $1(0.8,1.3)$ & $0.4(0.3,0.4)$ & $27(10.6,52)$ & $16(0.2,21.7)$ & $6.2(4.9,7.3)$ & $3.9(2.3,7.9)$ \\
\hline \multirow[t]{2}{*}{ Frog } & $\mathrm{Ti}$ & 54 & $1.2(0.6,1.8)$ & $0.6(0.3,3.2)$ & $17.6(3.2,98.4)$ & $10.4(0.2,32.5)$ & $4.6(2,7.5)$ & $7.9(2.1,29)$ \\
\hline & Fr & 18 & $1.3(0.7,1.9)$ & $0.5(0.2,0.8)$ & $11.3(1.8,73.6)$ & $2.2(0.2,16.5)$ & $5(1.1,8.4)$ & $18.6(2.5,340)$ \\
\hline \multirow[t]{2}{*}{ Mullet } & $\mathrm{Ti}$ & 54 & $0.8(0.5,1.6)$ & $0.2(0.1,0.4)$ & $8.9(2.8,35.7)$ & $12.4(0.2,29.1)$ & $3.3(0.2,7.6)$ & $3.3(1.4,10)$ \\
\hline & $\mathrm{Fr}$ & 18 & $0.9(0.5,1.2)$ & $0.2(0.1,0.4)$ & $11.2(0.9,84.2)$ & $0.5(0.1,4.4)$ & $3.8(2,6.2)$ & $6.0(1.8,31)$ \\
\hline \multirow[t]{2}{*}{ Phillippi } & $\mathrm{Ti}$ & 18 & $1(0.6,1.2)$ & $0.3(0.2,0.4)$ & $12.1(4.5,22.6)$ & $13.8(0.3,24.8)$ & $4.7(2.5,8.3)$ & $7.3(4.5,10)$ \\
\hline & Fr & 6 & $1.1(1,1.2)$ & $0.4(0.3,0.4)$ & $41.8(4.6,108.6)$ & $1.3(0.3,4)$ & $3.5(1.7,4.5)$ & $4.6(3.3,6.3)$ \\
\hline \multirow[t]{2}{*}{ Powell } & $\mathrm{Ti}$ & 18 & $1(0.7,1.3)$ & $0.2(0.1,0.3)$ & $12.2(1.6,45.2)$ & $2.9(0.2,7)$ & $3.1(1.8,7.8)$ & $3.8(0.8,14)$ \\
\hline & Fr & 6 & $0.7(0.5,1.1)$ & $0.2(0.1,0.3)$ & $5(1.5,18.5)$ & $0.3(0.2,0.4)$ & $3.4(2.3,4.5)$ & $4.3(1.6,12)$ \\
\hline \multirow[t]{2}{*}{ South } & $\mathrm{Ti}$ & 54 & $0.9(0.4,1.5)$ & $0.2(0.1,0.4)$ & $13.9(0.8,66)$ & $21.3(0.3,32.8)$ & $3.6(0.7,7.2)$ & $6.6(3.3,10)$ \\
\hline & $\mathrm{Fr}$ & 18 & $1.2(0.6,1.7)$ & $0.1(0.1,0.4)$ & $13.6(1.5,64.6)$ & $1.5(0,20.4)$ & $5.4(1.6,9.6)$ & $5.7(2.2,16)$ \\
\hline \multirow[t]{2}{*}{ Spring } & $\mathrm{Ti}$ & 18 & $1.1(0.8,2)$ & $0.1(0,0.2)$ & $30.7(3,140.4)$ & $10.1(0.4,20)$ & $2.7(1.2,4.2)$ & $5.3(2.8,7)$ \\
\hline & Fr & 6 & $0.8(0.7,0.9)$ & $0.1(0,0.1)$ & $5.4(1.8,11.3)$ & $1.4(0.2,6.5)$ & $6(3.6,7.1)$ & $6.2(2.3,20)$ \\
\hline \multirow[t]{2}{*}{ Sugarhouse } & $\mathrm{Ti}$ & 18 & $1.3(0.8,2.3)$ & $0.4(0.2,0.8)$ & $30.1(2,153.6)$ & $11.1(0.2,23)$ & $4.7(2.7,6.3)$ & $3.3(0.9,9.6)$ \\
\hline & Fr & 6 & $0.9(0.6,1.2)$ & $0.3(0.2,0.3)$ & $6.5(1.6,22.2)$ & $1.4(0.4,4.4)$ & $3.6(2.2,4.4)$ & $10.5(2,70)$ \\
\hline \multirow[t]{2}{*}{ Sweetwater } & $\mathrm{Ti}$ & 54 & $0.8(0.6,1.3)$ & $0.2(0.1,0.3)$ & $13.1(1.6,88.8)$ & $10.7(0.1,25.4)$ & $3.7(1.5,8.2)$ & $7.5(3,21)$ \\
\hline & Fr & 18 & $0.8(0.4,1.1)$ & $0.1(0,0.3)$ & $6.2(1.3,29.5)$ & $0.2(0,0.4)$ & $6.7(1.7,11.6)$ & $6.3(2.3,34)$ \\
\hline \multirow[t]{2}{*}{ West Spring } & $\mathrm{Ti}$ & 54 & $0.8(0.5,1.2)$ & $0.2(0.1,0.4)$ & $19.6(2.8,88.3)$ & $18.2(3.2,32.1)$ & $5.3(2.4,8.9)$ & $4.3(0.6,1.2)$ \\
\hline & $\mathrm{Fr}$ & 18 & $0.8(0.5,1.2)$ & $0.2(0,0.4)$ & $30.4(0.7,110.4)$ & $5.8(0.3,26.6)$ & $3.7(1.9,7.6)$ & $3.4(1.1,7.1)$ \\
\hline \multirow[t]{2}{*}{ Wildcat } & $\mathrm{Ti}$ & 18 & $1.1(0.8,1.4)$ & $0.3(0.2,0.5)$ & $22.7(4.1,75.3)$ & $6.8(0.5,13.9)$ & $5.7(3.4,7.4)$ & $4.8(0.9,15)$ \\
\hline & $\mathrm{Fr}$ & 6 & $1.2(0.9,1.4)$ & $0.6(0.3,1.2)$ & $13.5(0.3,40.7)$ & $1.9(0,4.5)$ & $4.4(1.5,8.3)$ & $7.2(3.2,20)$ \\
\hline
\end{tabular}

minimum and maximum in parentheses. Portion describes the tidal (Ti) or freshwater (Fr) sections of each creek 

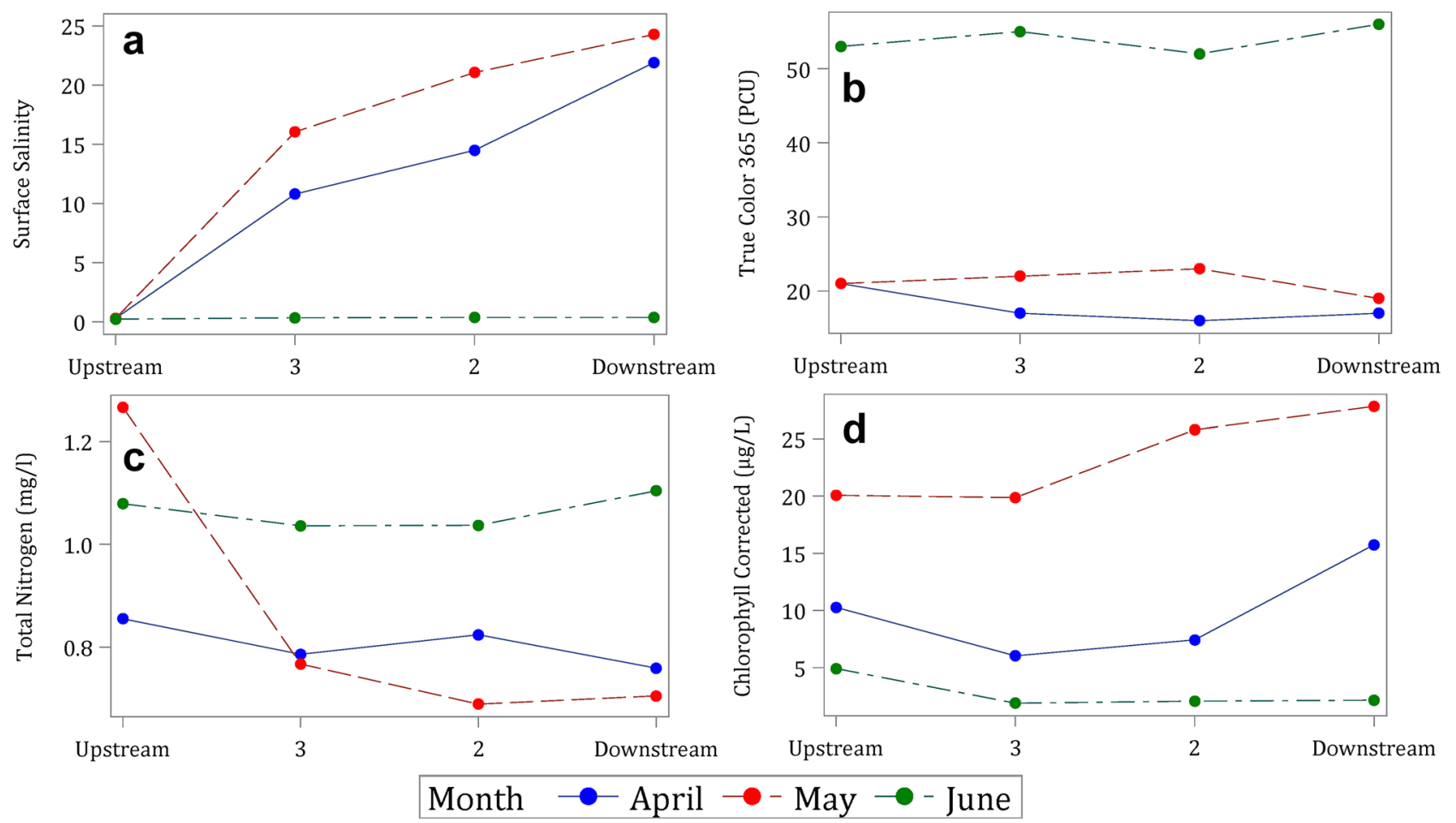

Fig. 4 Instream water quality dynamics for three consecutive sampling events in Estero River in April (solid line), May (broken line) and June (dashed line) of 2017 where 14 day antecedent rainfall totals were $0.5 \mathrm{~cm}, 4.3 \mathrm{~cm}$, and $31.5 \mathrm{~cm}$, respectively. The $\mathrm{x}$-axis shows the upstream freshwater site on the left and three sites in the tidal portion of the system with distance downstream to the right. Plots reflect distributions of surface salinities (a), true color (b), total nitrogen concentrations (c), and chlorophyll $a$ concentrations (d) cephalus), and sheepshead (Archosargus probatocephalus) as well as a number of species that serve as prey items for estuarine dependent sport fish (Janicki Environmental and Mote 2016). Catch per unit effort of snook aggregated across the sampled creeks was significantly higher in the tidal creeks we sampled compared to larger tidal river systems in Tampa Bay routinely sampled by partners over the same period of time (Fig. 6), confirming that these creeks are critical habitats that serve as nurseries supporting snook early life stages. The length frequency distribution of snook captured in this study included both young of the year and age 1 snook which are underrepresented in data currently being utilized for snook stock assessments. However, snook catch, including density, length frequency or biomass, was not significantly correlated with nutrient concentrations in our study and assessments of the fish community composition suggested that while there were substantial differences between creeks, fish diversity metrics (after removing exotic species) were either not significantly or positively correlated with observed nutrient concentrations (Table 3 ).

The results of our field surveys suggested that underlying stressor-response relationships were likely affected by characteristics of the watershed, nutrient inputs from both natural and anthropogenic sources, and physical characteristics of the creek itself. Even our most natural creeks had some evidence of anthropogenic impacts and the interaction among many types of anthropogenic influences limited our ability to identify unifying water quality thresholds that would provide both sensitivity in identifying creeks with nutrient related impairments to the response endpoints we tested while also providing specificity in identifying creeks where similar nutrient concentrations were not resulting in imbalances of flora and fauna that would be deleterious to creek condition. The conditional nature of these relationships was confirmed by conditional inference models which suggested that a large combination of habitat-related factors were required to explain substantial proportions of the variation in water quality response endpoints. The most influential drivers for nutrient concentrations included creek length and watershed buffer area characteristics (including agricultural areas within the buffer) while Chla responses were more influenced by other instream water quality characteristics (Table 4). The degree of impervious surface in the watershed was a significant but not dominant predictor of instream nutrient of chlorophyll concentrations in our study; perhaps due to the heavily urbanized nature of much of our 


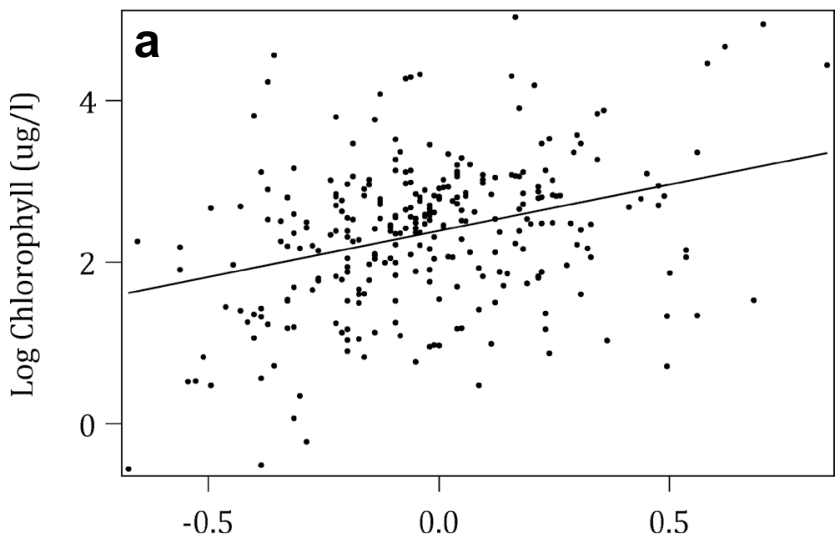

Log Total Nitrogen $(\mathrm{mg} / \mathrm{l})$

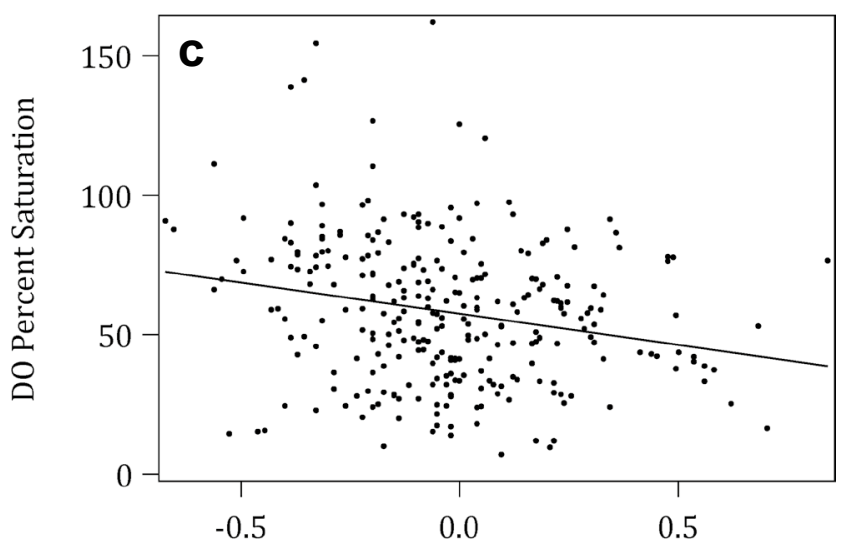

Log Total Nitrogen (mg/l)

Fig. 5 Bivariate stressor-response relationships across creeks for natural log transformed total nitrogen and natural log transformed chlorophyll a concentrations (a), natural log transformed total phosphorus and natural log transformed chlorophyll a concentrations (b), natural

study area. Detailed results evaluating the many aspects of this multidisciplinary study including investigating relationships between fish catch and Chla and DO conditions, water quality comparisons between creeks, and water quality dynamics along the salinity gradient can be found in Janicki Environmental and Mote (2016 and 2019).

Table 2 Results of bivariate linear water quality regression analysis. Coefficients of determination $\left(\mathrm{R}^{2}\right)$ and (Akaike Information Criteria (AICC1) are based on models with no random effects. AICC2 is the AICC result for models with random creek intercepts. AICC3 is the result for models incorporating both random intercepts and residual
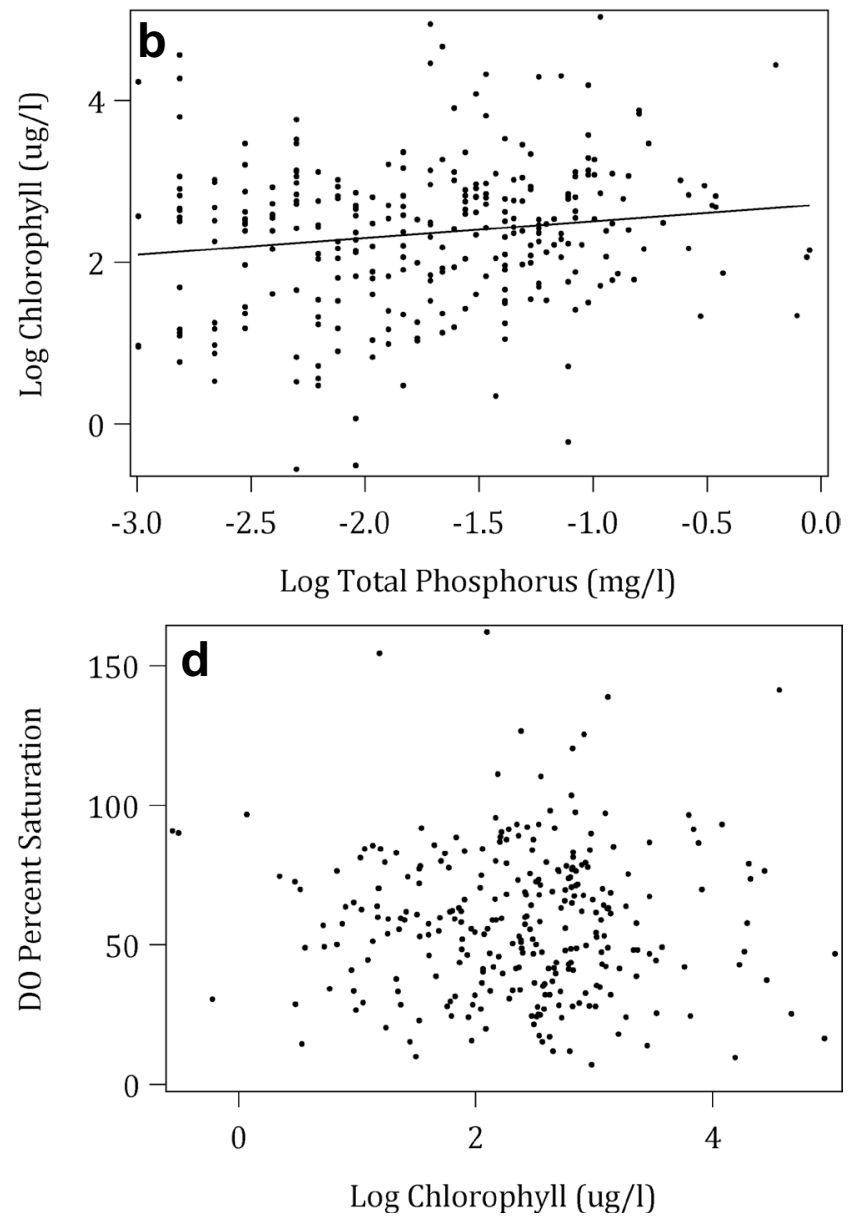

log transformed total nitrogen and dissolved oxygen percent saturation (c), and natural log transformed chlorophyll $a$ concentrations and dissolved oxygen percent saturation (d)

The remainder of this paper focuses on the development and application of our assessment framework. Instead of proposing a single criterion value that would likely be mis-specified for a large proportion of creeks within the systems, we developed an assessment framework that was completely outside of any regulatory

correlation. Intercepts and slopes are provided for models with the lowest AICC with asterisks representing significance levels for slope effects $(*=p<0.05, * *=p<0.01, * * *=p<0.001)$ and ns representing non-significant effects

\begin{tabular}{llllllll}
\hline Response & Predictor & $\mathrm{R}^{2}$ & AICC1 & AICC2 & AICC3 & Intercept & Slope \\
\hline Chla & TN & 0.10 & 743 & 708 & 708 & 2.39 & $1.29 * * *$ \\
Chla & TP & 0.02 & 770 & 714 & 713 & 3.6 & $0.72 *$ \\
DO $_{\text {SAT }}$ & TN & 0.05 & 2654 & 2588 & 2584 & 57.4 & $-26.29 * * *$ \\
DO $_{\text {SAT }}$ & Chla & 0 & 2671 & 2608 & 2604 & ns & ns \\
\hline
\end{tabular}




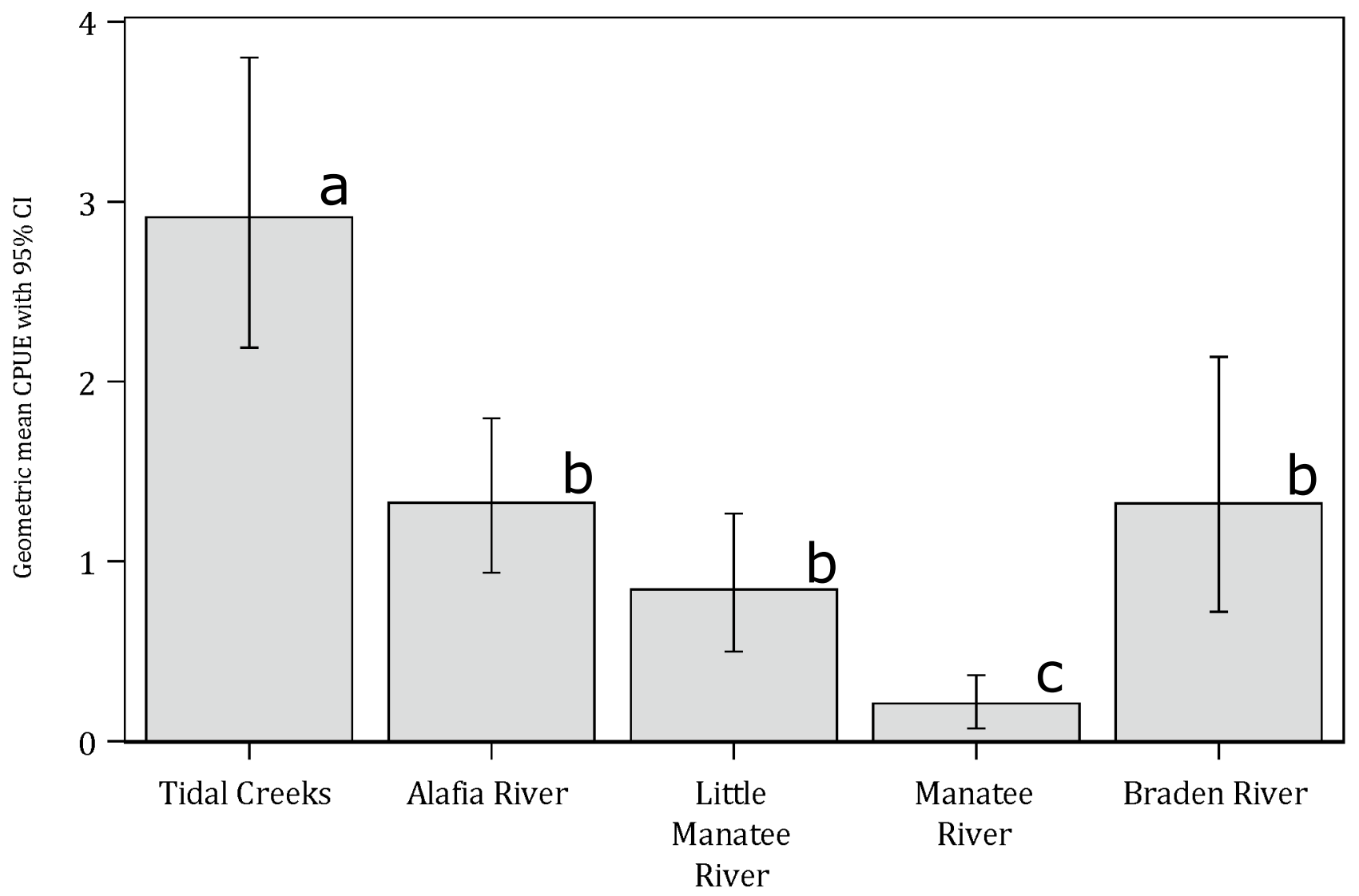

Fig. 6 Catch per unit effort $\left(100 \mathrm{~m}^{2}\right)$ for common snook (Centropomus undecimalis) collected in tidal creeks between November 2013 and September 2014 (far left) and in four larger tidal rivers in Tampa Bay routinely sampled with similar gear types over the same period

of time. Letters correspond to statistically significant different groups based on ANOVA with post hoc Tukey test adjustment for multiple comparisons

framework but that could be used by the NEPs and their partners as a screening and prioritization tool to target creeks at risk of nutrient related adverse effects for future investigation and research. The assessment framework includes a nutrient report card and evaluation of

a number of water quality indicators developed to provide more site-specific insights on contributing factors to observed adverse effects related to alterations in the system that reduce assimilative capacity and resiliency to nutrient inputs.

Table 3 Results of Spearman rank correlations between creek median fish community diversity metrics and creek geometric average benthic and water column chlorophyll a concentrations, total nitrogen concentrations and total phosphorus concentrations. Fish diversity

metrics included median Shannon Weiner diversity $\left(H^{\prime}\right)$, Margalef's species richness $(D)$, Pielou's evenness $\left(J^{\prime}\right)$, number of individuals, and number of species

\begin{tabular}{|c|c|c|c|c|c|}
\hline \multirow[t]{2}{*}{ Response endpoint } & \multicolumn{5}{|c|}{ Fish diversity metric } \\
\hline & Margalef & Pielou & Shannon & \# Individuals & \# Species \\
\hline Benthic chlorophyll (mg/sqm) & $-0.53 *$ & $-0.59 *$ & ns & ns & ns \\
\hline Water column chlorophyll a $(\mu \mathrm{g} / \mathrm{l})$ & ns & ns & ns & ns & ns \\
\hline Total nitrogen $(\mathrm{mg} / \mathrm{l})$ & ns & ns & ns & ns & ns \\
\hline Total phosphorus (mg/l) & $0.72 * *$ & $0.64 * *$ & $0.66 * *$ & ns & $0.66^{* *}$ \\
\hline
\end{tabular}


Table 4 Results of conditional probability analysis using RandomForest bootstrap implementation. Predictor variables listed represent sets of water quality and habitat metrics in the sampled creeks most important in defining relationships with the response variable

\begin{tabular}{|c|c|c|}
\hline Response & Predictor & $\begin{array}{l}\text { Percent of } \\
\text { variance } \\
\text { explained }\end{array}$ \\
\hline Water column average (DO \% sat) & $\begin{array}{l}\text { Colored dissolved organic matter, total nitrogen, orthophosphate, watershed hydrologic unit } \\
\text { area load, proportion of buffer classified as natural, creek salinity class }\end{array}$ & $42.03 \%$ \\
\hline Water column chlorophyll & $\begin{array}{l}\text { Total kjeldahl nitrogen, total nitrogen, ammonia, turbidity, proportion of buffer classified as } \\
\text { natural }\end{array}$ & $46.84 \%$ \\
\hline Total nitrogen & $\begin{array}{l}\text { Creek length, total phosphorus, colored dissolved organic matter, turbidity, orthophosphate, } \\
\text { proportion of agriculture in the buffer, acreage of golf course in the watershed, natural } \\
\text { buffer proportion, and the number of outfalls in the surveyed portion of the creek }\end{array}$ & $69.97 \%$ \\
\hline Total phosphorus & $\begin{array}{l}\text { Creek length, TN, proportion of agriculture in the buffer, TKN, acreage of golf course in } \\
\text { the watershed, proportion of buffer classified as natural, and the number of outfalls in the } \\
\text { surveyed portion of the creek }\end{array}$ & $84.24 \%$ \\
\hline Benthic chlorophyll (BMAC) & $\begin{array}{l}\text { Salinity, orthophosphate, colored dissolved organic matter, proportion of buffer classified } \\
\text { as natural, creek length, total phosphorus, and ammonia }\end{array}$ & $20.27 \%$ \\
\hline Chlorophyll ratio & $\begin{array}{l}\text { Total kjeldahl nitrogen, total nitrogen, ammonia, nitrate, turbidity, proportion of buffer clas- } \\
\text { sified as natural, orthophosphate, total phosphorus, and colored dissolved organic matter }\end{array}$ & $34.05 \%$ \\
\hline
\end{tabular}

\section{Management Applications}

\section{Report Card}

Report card outcomes for the period of record 2009 to 2018 are mapped in Fig. 7. Ninety-eight creeks (108 WBIDs) within the population had data collected within the 10 year assessment period. Of those WBIDs with data, 13 were assigned as Prioritize, 16 as Investigate, and 10 as Caution (Fig. 8). The remaining 69 WBIDs with data were assigned to the Monitor category indicating that nutrient conditions in these creeks were likely not adverse to the biological endpoints we measured. The majority of WBIDs had no data reported during the assessment period, highlighting the need for more monitoring to support stewardship of these resources.

The flexibility of the scoring algorithm to classify a creek can be seen by the shading of cells in Fig. 8 which depicts the frequency of years classified into each category. While most creeks had multiple years of data, 27 creeks had data only for a single year; however, the utility of evaluating even a single year was highlighted by our findings that several of these creeks exhibited nitrogen concentrations above our Caution criteria. This information is critical in data limited systems. Several creeks in the Investigate or prioritize categories had only episodic spikes in nitrogen concentrations and several years of data where TN concentrations were below the margin of safety providing important information on nutrient inputs to the system while other systems were consistently above the threshold for the Investigate category.

The cumulative distributions of the TN AGMs for each report card category were visually distinct across the range of observations (Fig. S3). The distribution of AGMs for creeks in the Prioritize category was right-skewed with the majority of AGMs exceeding their respective contributing freshwater nitrogen criterion values. However, several of these tidal creeks are not listed as impaired under the traditional, narrative regulatory assessments that rely on indirect assessments of nutrients to identify an "imbalance of flora and fauna." The Caution and Investigate categories were similar to each other for the lower quartiles of their respective distribution, but differed in the upper quartiles where the Investigate distribution was slightly right-skewed. The Investigate distribution had, by definition, at least one AGM concentration for $\mathrm{TN}$ above the prescribed margin of safety, explaining the difference at the upper tails. The Caution category was site-specific to protect smaller creeks from elevated TN concentrations, and an observed overlap with the Investigate category for larger creek systems was not unexpected, as larger creeks grading category thresholds were higher.

\section{Tidal Creek Indicators}

The report card is one aspect of the larger assessment framework to evaluate tidal creek condition. The development of indicators to evaluate site-specific water quality attributes was based on results from our study and the generalization of those results to the larger population of creeks. For example, despite weak linear relationships, conditional probability analysis suggested a highly significant difference $(p<0.001)$ in Chla based on a TN concentration threshold of $1.1 \mathrm{mg} / \mathrm{l}$. When $\mathrm{TN}$ concentrations were at or below $1.1 \mathrm{mg} / \mathrm{l}$, the median Chla was below the current regulatory numeric interpretation of the narrative criterion (i.e. Chla AGM of $11 \mu \mathrm{g} / \mathrm{l})$ applied to tidal creeks. This threshold TN 


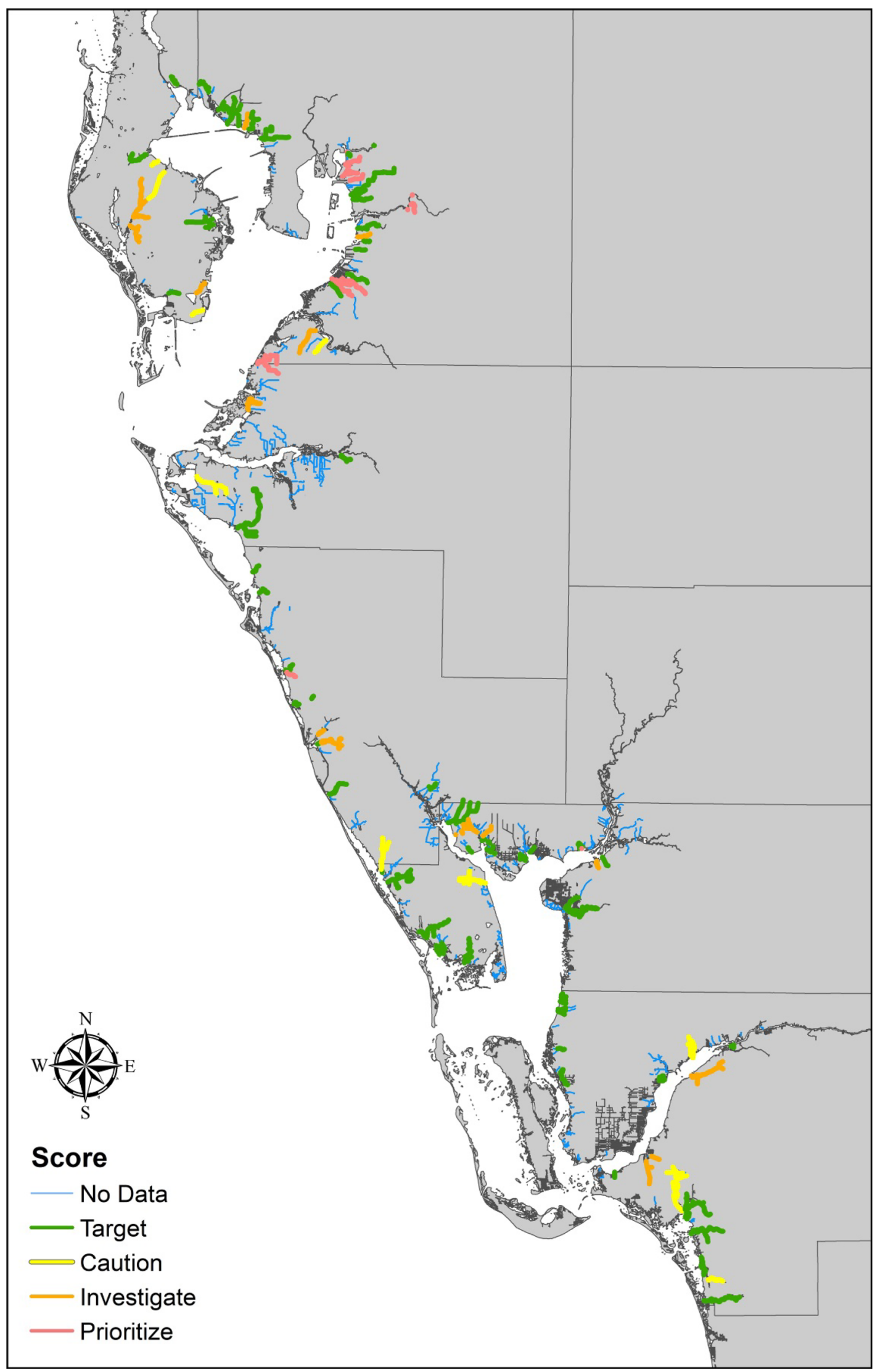

Fig. 7 Application of tidal creek nitrogen report card to the population of southwest Florida tidal creeks 


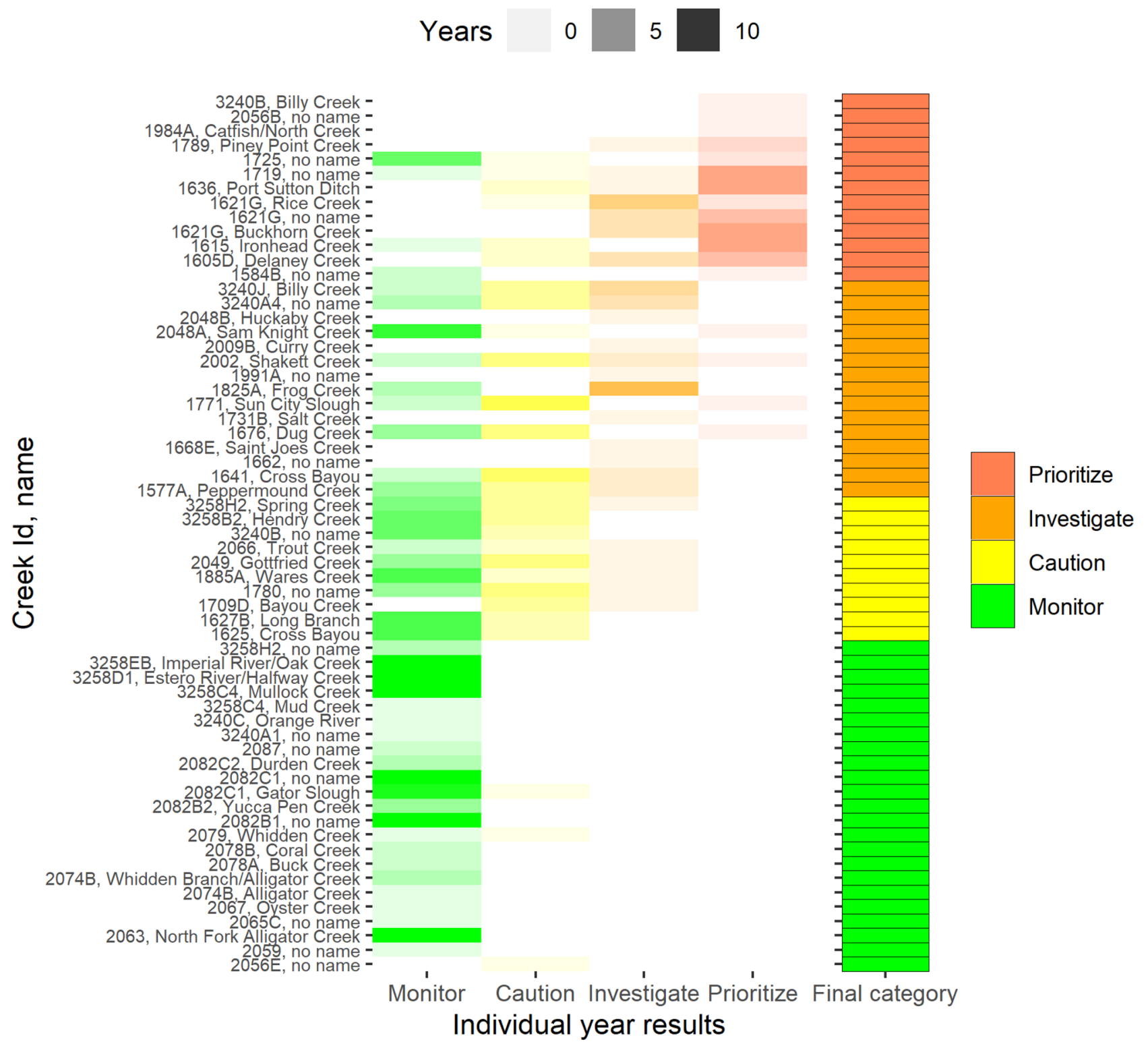

Fig. 8 Summary of prioritized creeks displaying categorized annual outcomes (first four columns) and the final report card score (final column). Cells in the first four columns are shaded (opacity) by

concentration is similar to the median value of creeks in the Caution category $(1.1 \mathrm{mg} / \mathrm{l})$, as well as a screening level $\mathrm{TN}$ indicator (1.2 $\mathrm{mg} / \mathrm{l}$ annual average) previously used for Florida estuaries (Paulic et al. 1996). Therefore, an AGM $\mathrm{TN}$ of $1.1 \mathrm{mg} / \mathrm{l}$ was identified as one indicator of tidal creek condition.

Carstensen et al. (2011) used the ratio of Chla per unit TN $(\mathrm{Chla} / \mathrm{TN})$ as an indicator of a shifting ecological baseline in the relationship between the two water quality constituents and we considered this ratio as a useful indicator of phytoplankton response to nutrient inputs in tidal creeks. In our study, tidal creeks with median Chla/TN ratios higher than the number of years that were assigned to each category within the 10 -year evaluation period

15 were observed to have a greater degree of physical alteration to either creek morphology or source water hydrology (West Spring, Forked, and Buck Creeks; Fig. S4) though the degree of physical alterations was difficult to quantify. Physical alterations to creek morphology are common in southwest Florida and can alter residence times and disrupt the natural hydrologic regime, affecting creek biogeochemistry and ecology. A high Chla/TN ratio may indicate more autotrophic conditions, while extremely low ratios may indicate dysfunction in expected nutrient assimilation pathways that manifest as Chla. Based on our observation that tidal creeks with median Chla/TN ratios higher than 15 tended to 
have a greater degree of physical alteration to the system, an annual median Chla/TN ratio of 15 was identified as another indicator of creek condition.

Inorganic nitrogen is readily assimilated by biological processes in nitrogen-limited systems and is also a common indicator of anthropogenic inputs (Gowen, 1992). Inorganic nitrogen was typically assimilated rapidly along the length of the creeks in our study, indicating that the dilution or uptake of inorganic nitrogen by biological processes could be a useful indicator of creek condition. However, there were cases where inorganic nitrogen inputs within the tidal portion of the creek were observed, indicating potential anthropogenic inputs. A plot of the source water and tidal inorganic nitrogen concentrations relative to a 1:1 line (Fig. S5) was used to identify creeks that may have anthropogenic inputs within the tidal portion of the creek. In our study, Estero River was a consistent example having an inorganic source of nitrogen of currently unknown origin within the tidal portion of the system. We included this ratio with a threshold value of 1 as an indicator of inorganic nitrogen inputs into the tidal portion of the creek though its assessment requires sampling at locations in both the tidal and freshwater portions of the creek.

Florida's Trophic State Index (TSI) (Paulic et al. 1996) was used as a water quality screening tool for Florida lakes and estuaries prior to the development of more site-specific criteria and was included as a tidal creek indicator to evaluate the utility of a composite index, combining both Chla and $\mathrm{TN}$ (and in some cases TP, depending on the N/P ratio). The Florida TSI is a modification of Carlson's (1977) Trophic State Index that excludes water clarity due to the blackwater characteristics of Florida waters but combines measurements of Chla, TN, and TP concentrations into a single value ranging from 0 to 100 to describe a waterbody's trophic state, with higher values suggesting more eutrophic, degraded conditions. For Florida lakes, values above 70 are rated a "poor" condition, values from 60 to 69 are "fair," and values below 60 are rated "good." Category breakpoints for Florida estuaries are ten points lower to reflect a lower productivity relative to lakes (Paulic et al. 1996). Application of the Florida TSI to the population of tidal creeks in our study resulted in a median value of 47 suggesting the majority of creek years were in the "good" estuary category. Scores ranged from 17 and 87 with only $5 \%$ of the scores above the threshold used to denote a poor estuary (TSI 60, Fig. S6). We selected a threshold value to a TSI threshold score of 55, the midpoint of a "fair" estuary, to indicate that the productivity of a creek may be shifting towards a more eutrophic condition.

An example synthesis of our multimetric indicator results, which include the 4 indicators described above as well as the regulatory Chla and DO standards currently used to evaluate tidal creeks under the narrative criterion, is provided for four example creeks in Fig. 9 using radar charts. The radar charts present the percentage of annual evaluations that exceed the threshold values for each indicator. For example, Fig. 9a displays results for a tidal creek with a high percentage of TN indicator exceedances, high percentage of Chla exceedences, a high number of dissolved oxygen exceedances (i.e. dissolved oxygen below the threshold criteria), and the majority of years above the selected TSI threshold value. This creek conforms to the traditional management paradigm where high nutrient concentrations are correlated with high Chla and low DO conditions. Figure 9b depicts an outcome with no TN indicator scores above the $1.1 \mathrm{mg} / \mathrm{l}$ threshold, but the majority of years exceeding the regulatory standards for both Chla and DO. The nitrate ratio threshold in this creek was consistently exceeded indicating that despite relatively low $\mathrm{TN}$, nitrate inputs into the tidal portion of the creek were evident. This combined with the high exceedance of the Chla/TN ratio thresholds indicates that this creek may be particularly susceptible to inorganic nutrient inputs and/or be highly physically altered, requiring a more site-specific management approach. Figure 9c depicts results for a creek where the TN indicator score and TSI score were consistently exceeded but other metrics were not. The creek represented by Fig. 9d had high nitrate ratio score and TSI exceedences despite TN AGMs typically less than $1.1 \mathrm{mg} / \mathrm{l}$. The Chla AGMs were routinely exceeded, and the $\mathrm{Chla} / \mathrm{TN}$ ratio was exceeded in the same years indicating this creek may also be susceptible due to physical alterations or inorganic nutrient inputs. Together, these results highlight the complex interaction among individual water quality indicators and the need for additional information to supplement current narrative based tidal creek water quality standards. The radar charts provide an easy way to summarize multi-metric indicators and provide insights into sitespecific attributes that may govern water quality responses in our tidal creeks. This information can be used to inform site-specific investigations into tidal creek condition. The application of these tools using the open science dashboard provides an efficient platform for synthesizing and disseminating this information and allows the underlying science to advance over time.

\section{The Management Framework as an Open Science Product}

The tidal creeks dashboard (https://shiny.tbep.org/tidalcreekdash/; Beck and Wessel 2021) was created to leverage open science concepts that enable transparency, reproducibility, and accessibility of methods. The dashboard provides a simple user interface to the tidal creeks assessment results and the underlying methods and source code are freely available in the supporting "tbeptools" R package (Beck et al. 2021; https://tbep-tech.github.io/tbeptools/articles/tidalcreeks.html). This approach facilitates understanding of the assessment 

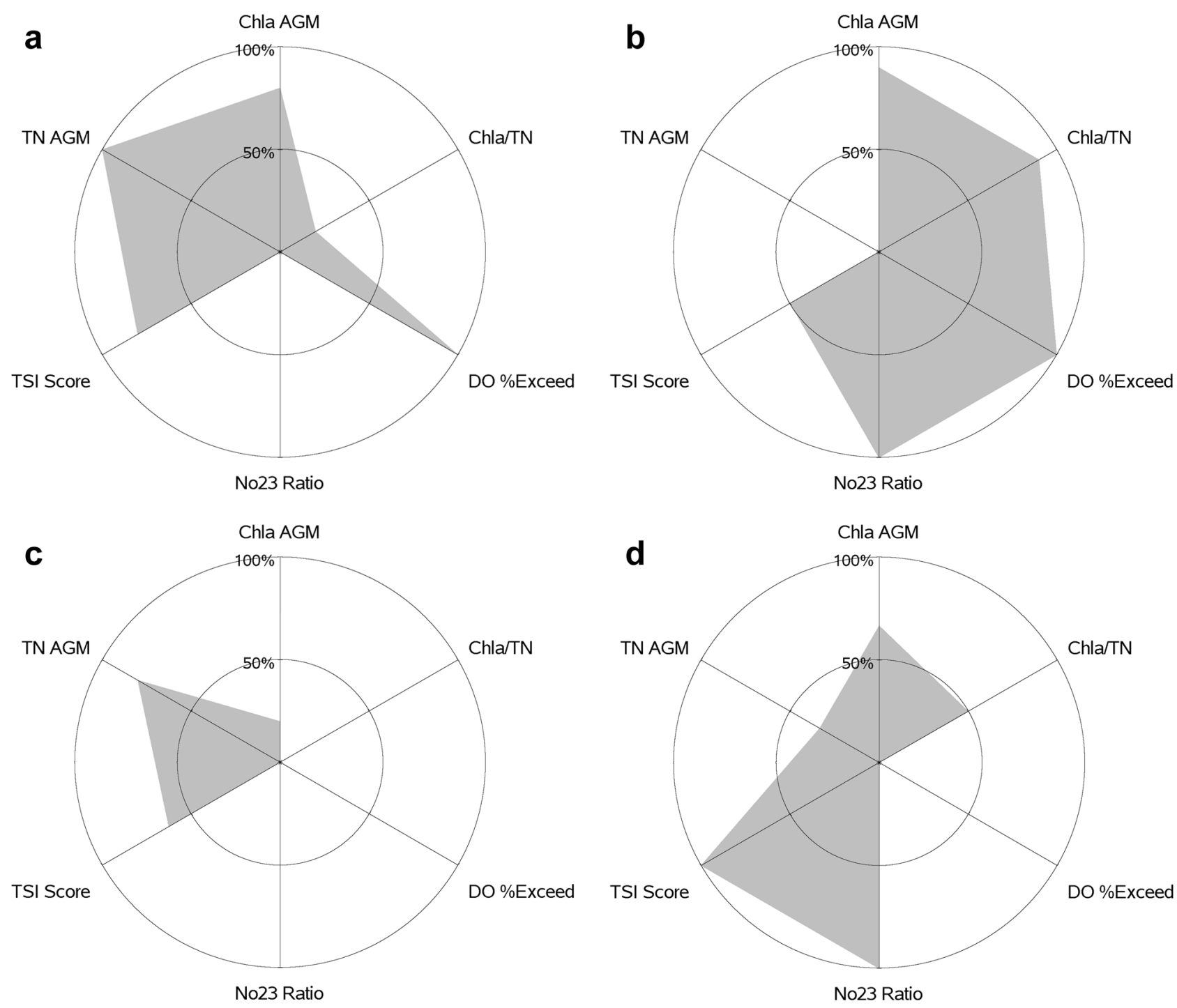

Fig. 9 Radar plots summarizing indicator results for four representative tidal creeks. Length of the radius represents the percentage of sampled years the threshold value was exceeded. Outer circle represents $100 \%$, and inner circle represents $50 \%$ of years exceeded, respectively

framework among stakeholders and can also encourage others to apply similar techniques by providing access to underlying code behind the analysis methods. Such approaches have been shown to promote "better science in less time" (Lowndes 2017). There are several components of the dashboard that facilitate understanding of the assessment framework. The main components include an overview page that describes how to use the dashboard and a brief summary of the methods, a report card page that provides mapped and summary outcomes for the population of creeks, and an indicator page to show detailed results for each creek. A useful component of the dashboard for local resource managers is the ability to select broad regions or specific creeks of interest. For example, an interactive map for the report card page allows the user to draw a custom polygon over an area of interest to select creeks within a particular jurisdiction. Results for creeks within the polygon are then shown in tabular format for download and also summarized by percentage in each reporting category, either by the number of creeks or by total creek length. The indicator page allows a user to select a particular creek to view detailed results including a complete time series of the ten years of data for TN and supporting indicators described above (e.g., Chla, TSI, DO). This provides managers additional context to understand site-specific creek condition within the context of the population. The ability to interact with and extract results of interest for specific creeks provides unlimited customization to retrieve results of interest, helping facilitate an understanding of larger patterns while also informing more detailed assessments that can better guide discrete and/or regional management activities. 
The open science aspects also facilitate broader adoption and application of these methods beyond southwest Florida.

\section{Discussion}

The assessment framework was developed to provide actionable outcomes for southwest Florida tidal creeks based directly on commonly collected water quality data reported in state and federal repositories. Outcomes can be used to identify and prioritize natural resource investigations and management actions for these tidal creeks, while also promoting and accelerating additional research that may be needed to better understand these systems. The adaptive management paradigm is promoted and facilitated by the open science application of the dashboard. The nitrogen report card characterizes concentrations relative to criteria established for contributing freshwater streams while the indicators provide context to the report card outcomes by evaluating other water quality metrics as well as nutrient dynamics between the fresh and tidal portion of the creek where data are available. It is important to note that the assessment framework is not a regulatory tool but is designed to complement existing regulatory assessments related to nutrient impacts in southwest FL tidal creeks and, if pursued in a proactive manner, may even preclude the need for more stringent regulatory interventions in some cases.

The report card outcome categories of Prioritize, Investigate, Caution, and Monitor provide local natural resource managers needed information from which to allocate limited resources to prioritize and pursue potential nutrient management activities. Several creeks identified as Prioritize or Investigate by our report card have current or legacy anthropogenic nutrient sources that have/had the potential to deliver large nutrient loads to the downstream estuary. In several cases, these tidal creeks would pass an "impairment" assessment utilizing the current narrative regulatory standards. Although the Caution category is based on a somewhat weak relationship between creek length and nitrogen concentrations, it was chosen as a precautionary measure to protect smaller creeks from elevated nutrients concentrations. As such, follow-up assessments using the indicator outcomes are designed to support the ultimate decision making process developed from initial report card grade. The report card utilizes data from both long-term monitoring programs and synoptic studies and has proven useful as a screening tool to characterize tidal creek condition even when only very limited data are available. We observed that even using a single year's worth of data in the assessment could be very informative. In one case, a creek was categorized into the Investigate category based on only 4 samples and subsequent investigations identified additional data associated with a point source discharge in this creek that was not represented in the statewide data repository. Resource managers can use the dashboard application to easily facilitate these types of desktop evaluations.

Our study results suggested nitrogen limitation for the majority of southwest Florida tidal creeks, and therefore, our report card was based on $\mathrm{TN}$ (the form of nitrogen used to establish numeric nutrient criteria for regulatory assessments in Florida with the exception of springs). However, the report card is easily adaptable to cases where phosphorus may be identified as the limiting nutrient or when colimitation of both nutrients may be important for a particular system. A large portion of our study area is characterized by a phosphorus rich sediment layer in west central Florida known as the "Bone Valley," resulting in high surface water phosphorus concentrations relative to other surface waters of the State; though, we did observe some creeks south of the Caloosahatchee River (Estero River and Spring Creek) that exhibited N/P ratios indicative of potential for phosphorus limitation at times. Consistent with Cloern et al. (2020), our results also suggested that there was substantial variability in N/P ratios dependent upon location along the tidal gradient, seasonality, and which elemental form was evaluated. The range of nutrient and Chla concentrations we observed was extremely similar to those reported for North Carolina tidal creeks (Mallin et al. 2004) where nutrient addition bioassay experiments suggested nitrogen may be limiting even with $\mathrm{N} / \mathrm{P}$ ratios are variable. However, we do not completely rule out the potential for phosphorus limitation under certain conditions in some locations within our study area.

Our field surveys supported indicator development useful in identifying site-specific attributes related to the water quality dynamics and the expression of nutrient inputs in these systems. In lakes and open bay estuarine systems, stressor-response relationships between nutrients and chlorophyll $a$ can be reliable as residence times are generally sufficient for phytoplankton reproduction if a sufficient mass of limiting nutrients is available. In fluvial systems including tidal creeks, nutrient-chlorophyll relationships are more complex. In fact, Florida's freshwater stream numeric nutrient criteria (62-302.531 F.A.C.) were based on a reference system approach due to an inability to define a stressorresponse relationship that would serve as unifying protective criteria for freshwater streams. The regulatory requirements for freshwater streams now include a biological confirmation step using stream condition index scores and periphyton indices to validate or supersede outcomes based on application of regulatory water quality criteria. Evidence from our tidal creeks study suggested that nutrient-chlorophyll relationships are mediated by physical alterations to the system and the form of nitrogen available, as well as riparian buffer and landscape attributes. Together, these site-specific confounding factors limited the ability to derive a single 
nutrient threshold that would be protective of all creeks without being unnecessarily restrictive for many creeks with a robust fish community. Instead, a host of indicators was used to provide site-specific context to observed water quality and the report card outcomes.

The indicator outcomes we observed exemplify the broad range of responses even among creeks with similar nitrogen concentrations. We found the radar charts to be an intuitive way to facilitate evaluating these multi-indicator outcomes. Some creek responses appeared directly related to total nitrogen concentrations while others may be related to inputs of inorganic nitrogen (as measured by nitrate) in the tidal portion of the creek as well as physical alterations to the system that may make certain creeks more susceptible to nutrient pollution than others. Typically, nitrates are rapidly assimilated by biological processes and the finding of exceedances in our nitrate ratio indicator was used to indicate the presence of a source (e.g. septics) in the tidal portion of the system. This outcome often correlated with exceedances of the Chla/TN ratio, though fewer creeks had nitrate measurements in both the tidal and contributing freshwater portion of the stream. The Chla/TN ratio adds further context as an indication of how nutrients are assimilated by water column phytoplankton in these systems. The Chla/TN ratio is also likely influenced by water residence time and may be a good surrogate descriptor of hydrological or physical alteration of a creek. Resource managers can use these metrics to pursue evaluations of nutrient sources and identify potential limiting physical conditions based on these outcomes. The TSI indicator was included to evaluate a composite water quality index within the assessment framework, but its utility as an indicator relative to the individual constituents that make up the TSI is still being evaluated.

Physical alterations of the landscape are critical components of tidal creek ecological condition (Holland et al. 2004; Sanger et al. 2015), and the southwest Florida landscape is dominated by highly urbanized areas but no single landscape level indicator stood out as a differentiator for tidal creek condition in our analysis. Anthropogenic effects were evident even in our most natural systems which could have affected these results and limited our ability to define a "reference system". Historically, many southwest Florida tidal creeks have been physically altered through dredging and channelizing for stormwater conveyance, flood control, recreation, and or navigation but have the same regulatory "designated use" for evaluating compliance with water quality standards under the Clean Water Act. These physical alterations can either dramatically increase the water volume relative to watershed size or disconnect the natural hydrology. Both of these conditions can significantly affect residence times, and it is interesting to note that hydrologic alteration is now being considered as a source of pollution within the USEPA Clean Water Act (Novak et al. 2016).
Ellis et al. (2017) suggested that creeks with relatively large discharge volumes could more efficiently dilute contaminant concentrations from terrestrial runoff compared to smaller, more urbanized creeks, suggesting the latter are more vulnerable to increased runoff from developed landscapes. Very few creeks in our study had both gaged flows and bathymetric data to estimate residence times, which is a current data gap critical to better understanding the role of freshwater discharge as a physical driver of water quality dynamics. The pursuit of additional indicators related to tidal creek condition, including the role of physical alterations on system function, the role of emergent wetland vegetation as a nutrient source and habitat, and the pursuit of additional biological response endpoints, is a recommended direction for future study.

Establishing biological response endpoints indicative of adverse effects to tidal creeks due to nutrient pollution was a challenging endeavor. The decision to use existing freshwater criteria values as the basis for the nutrient report card was based on the lack of evidence from our study that the response endpoints we evaluated were more sensitive to nutrient pollution than those identified for contributing freshwater criteria. Our study found that these creeks are critical habitats for several important fish species including the snook which supports similar findings by other studies in the region (Krebs et. al. 2007; Yeager et. al. 2007; Greenwood et. al. 2008; Sherwood 2010; Barbour and Adams 2012; Ley and Rolls 2018). Fish dose-response curves form the basis of the marine dissolved oxygen standard in Florida (FDEP 2013) that is currently applied to tidal creeks providing precedent for the use of fish as an indicator of adverse effects. However, neither individual species catch statistics nor community diversity metrics appeared to be adversely affected by the nutrient conditions we observed, even when those concentrations approached regulatory criteria for their contributing freshwater streams (Janicki Environmental and Mote 2016). This indicated that the faunal endpoints we evaluated may not be most sensitive to the effects of nutrient pollution. This finding does not diminish the importance of monitoring these creeks as fish habitat as our initial collaboration meetings established that a consensus of local resource managers view a healthy fish community as a primary goal for these systems which may also increase their assimilative capacity. While our goals are to continue to focus on developing robust biological response endpoints as indicators of tidal creek condition, our framework is currently based on commonly collected water quality data to provide an actionable list of creeks from which future research can focus to improve our understanding of the many aspect that constitute tidal creek biological integrity.

The three southwest Florida NEPs currently have dedicated management objectives in their individual Comprehensive Conservation and Management Plans that seek to identify indicators of tidal creek integrity and increase stewardship 
and management efforts in these systems. Development of this framework and its open science tools helps achieve those objectives. Currently, the assessment framework and dashboard allow natural resource managers to prioritize investigations into their tidal creeks and researchers to easily evaluate the distribution of nutrient and indicator conditions for these creeks to aid in developing future studies. The open science tools included in this study are expected to accelerate this effort both locally and in other regions where a water quality assessment framework for tidal creeks is desired. Extrapolation of these methods to other areas would require an accessible database with tidal creek water quality data, spatially referenced flow lines for tidal creeks, and numeric nutrient standards or management level thresholds for their contributing freshwater reaches. The assessment framework and the resulting open science tools are intended to assist resource managers in prioritizing investigative and proactive management actions in southwest Florida tidal creeks, thereby improving and accelerating the proper stewardship of these critical coastal habitats facing increased pressure from coastal landscape development, anthropogenic nutrient inputs, and climate change.

Supplementary Information The online version contains supplementary material available at https://doi.org/10.1007/s12237-021-00974-7.

\begin{abstract}
Acknowledgements The following participants were directly involved in implementing this study and are gratefully acknowledged for their commitment to the protection of southwest Florida tidal creeks: Felicia Burks, US Environmental Protection Agency, Mark Alderson, Sarasota Bay Estuary Program, Nicole Iadevaia, Coastal \& Heartland National Estuary Partnership, Gary Raulerson, Tampa Bay Estuary Program, Mark Flock, Sarah Malone, Rob Burnes and Robert McWilliams, Pinellas County, Tom Ash, Chris Pratt, Brett Ursin and Julie Christian Hillsborough County, Rob Brown, Greg Blanchard and Kerry Harkinson Manatee County, John Ryan, Sarasota County, Roger Debruler and Phillip Brouse Charlotte County, Brett O'Brien and Susan Fite Lee County, Dr. L. Kellie Dixon, Dr. Emily Hall, Camia Charniga, Dr. Nathan Brennan, and Dr. Ari Nissanka, Mote Marine Laboratory, Judith Ott (Volunteer), Jon Perry and Susan Janicki, Janicki Environmental, Inc., and Tim MacDonald and other members of the Florida Fish and Wildlife Conservation Commission's Fisheries independent Monitoring program too numerous to mention. In addition, the three anonymous ESCO reviewers are acknowledged for their insightful comments which substantially improved the manuscript.
\end{abstract}

Funding This project was funded in part by a US Environmental Protection Agency Wetlands Development Grant.

Open Access This article is licensed under a Creative Commons Attribution 4.0 International License, which permits use, sharing, adaptation, distribution and reproduction in any medium or format, as long as you give appropriate credit to the original author(s) and the source, provide a link to the Creative Commons licence, and indicate if changes were made. The images or other third party material in this article are included in the article's Creative Commons licence, unless indicated otherwise in a credit line to the material. If material is not included in the article's Creative Commons licence and your intended use is not permitted by statutory regulation or exceeds the permitted use, you will need to obtain permission directly from the copyright holder. To view a copy of this licence, visit http://creativecommons.org/licenses/by/4.0/.

\section{References}

Barbour, Andrew B., and Aaron J. Adams. 2012. Biologging to examine multiple life stages of an estuarine dependent fish. Marine Ecology Progress Series. 457: 241-250.

Beck, M.W., M. Schrandt, M. Wessel, E. Sherwood, and B. Best. 2021. tbeptools: utility functions for processing data from TBEP. $\mathrm{R}$ package version 0.0.1.

Beck, M.W., and M. Wessel. 2021. tbep-tech/tidalcreek-dash: v1.1 (Version v1.1). Zenodo. 10.5281/zenodo.3701560, Dashboard: shiny.tbep.org/tidalcreek-dash

Breiman, Leo. 2001. Random forests. Machine Learning 45 (1): 5-32.

Brown, Mark T., and Benjamin M. Vivas. 2005. Landscape development intensity index. Environmental Monitoring and Assessment 101 (1-3): 289-309.

Burghart, Scott E., David L. Jones, and Ernst B. Peebles. 2013. Variation in estuarine consumer communities along an assembled eutrophication gradient: Implications for food web instability. Estuaries and Coasts 36: 951-965.

Carlson, Robert E. 1977. A trophic state index for lakes. Limnology and Oceanography. 22 (2): 361-369.

Carstensen, Jacob, Maria Sanchez-Camacho, Carlos M. Duarte, Dorte Krause-Jensen, and Nuria Marba. 2011. Connecting the dots: Responses of coastal ecosystems to changing nutrient concentrations. Environmental Science and Technology 45: 9122-9132.

Castro, M.S., C.T. Driscoll, T.E. Jordan, W.G. Reay, and W.R. Boyton. 2003. Sources of nitrogen to estuaries in the United States. Estuaries 26 (803-814): 2003. https://doi.org/10.1007/BF02711991.

Chang, W., J. Cheng, J.J. Allaire, Y. Xie, and J. McPherson. 2020. shiny: web application framework for R. R package version 1.5.0. https://CRAN.R-project.org/package $=$ shiny.

Clark, P. A. 1987. Condition and management of Tampa Bay tidal tributaries. in: Webb, Frederick J., Jr. ed. Proceedings of the Fourteenth Annual Conference on Wetlands Restoration and Creation: May 14-15, 1987. pp. 88-102.

Clark, P. A. 1991. Management directions and needs for Tampa Bay tidal tributaries. in: Treat, S. F. and Clark, P. A. eds. Proceedings, Tampa Bay Area Scientific Information Symposium 2. 1991 February 27-March 1, Tampa, FL. pp. 497-510.

Clarke, K. R. and R. N. Gorley. 2006. PRIMER v6: user manual/tutorial. PRIMER-E Ltd: Plymouth, United Kingdom. 190 p.

Cloern, James E. 2001. Our evolving conceptual model of the coastal eutrophication problem. Marine Ecology Progress Series. 210: 223-253.

Cloern, James E., Tara S. Schraga, Erica Nejad, and Charles Martin. 2020. Nutrient status of San Francisco Bay and its management implications. Estuaries and Coasts 43: 1299-1317.

Crain, Caitlin Mullan. 2007. Shifting nutrient limitation and eutrophication effects in marsh vegetation across estuarine salinity gradients. Estuaries and Coasts 30 (1): 26-34.

Dame, Richard, Merryl Alber, Dennis Allen, Alice Chalmers, Robert Gardner, Craig Gilman, Bjorn Kjerfve, Alan Lewitus, Michael Mallin, Clay Montague, Jay Pinckney, and Ned Smith. 2000. Estuaries of the south Atlantic coast of North America: Their geographical signatures. Estuaries 23: 793-819.

Davison, A.C. and D.V. Hinkley. 2003. Bootstrap methods and their application. Cambridge University Press. $582 \mathrm{pp}$.

Deininger, Anne, and Helene Frigstad. 2019. Reevaluating the role of organic matter sources for coastal eutrophication, oligotrophication, and ecosystem health. Frontiers in Marine Science. 6: 210. https://doi.org/10.3389/fmars.2019.00210.

Ellis, Kathryn K., Timothy Callahan, Dianne I. Greenfield, Denise Sanger, Joshua Robinson, and Martin Jones. 2017. Measuring and modeling flow rates in tidal creeks: A case study from the 
central coast of South Carolina. Journal of South Carolina Water Resources 4 (1): 21-39.

Florida Administrative Code (F.A.C.) 62-302.530 Table: Surface Water Quality Criteria.

Florida Administrative Code (F.A.C.) 62-302.531 Numeric Interpretations of the Narrative Criteria.

Florida Department of Environmental Protection (FDEP). 2013. Technical Support Document: derivation of dissolved oxygen criteria to protect aquatic life in Florida's fresh and marine waters. Prepared by Florida Department of Environmental Protection Division of Environmental Assessment and Restoration. 232 pp.

Glibert, P.M., Madden, C.J., Boynton, W., Flemer, D., Heil, C. and Sharp, J., 2010. Nutrients in estuaries: a summary report of the national estuarine experts workgroup 2005-2007.EPA 68-c-02091. epa.gov/scitech/swguidance/standards/criteria/nutrients/ upload/Nutrients-inEstuaries-November-2010.pdf. Accessed 01NOV2020

Gowen, R.J.P., and Tett, and K. J. Jones. 1992. Predicting marine eutrophication: The yield of chlorophyll from nitrogen in Scottish coastal waters. Marine Ecology Progress Series. 85: 153-161.

Greenwood, M.F.D., D.D. Chagaris, T.C. MacDonald, R.E. Matheson, Jr., R.H. McMichael, Jr., R.F. Heagey, F.X. Courtney, G.V. Onorato and S.D. Stahl. 2008. Tampa Bay tidal tributaries habitat initiative: fish and fish habitat technical report. Report to the Tampa Bay Estuary Program. 290 pp.

Holland, A Frederick, Denise M. Sanger, Christopher P. Gawle, Scott B. Lerberg, Marielis Santiago, George H.M. Riekerk, Lynn E. Zimmerman, and Geoffrey I. Scott. 2004. Linkages between tidal creek ecosystems and the landscape and demographic attributes of their wetlands. Journal of Experimental Marine Biology and Ecology. 298: 151-178.

Hothorn, Torsten, Kurt Hornik, and Achim Zeileis. 2006. Unbiased recursive partitioning: A conditional inference framework. Journal of Computational and Graphical Statistics. 15: 651-674.

Janicki Environmental, Inc. and Mote Marine Laboratory. 2016. Southwest Florida Tidal Creeks Nutrient Study. Report prepared for the Sarasota Bay Estuary Program (Technical Report Number 2013SBEP17). Sarasota, FL.

Janicki Environmental, Inc. and Mote Marine Laboratory. 2019. Southwest Florida Tidal Creeks: Nutrient management framework and indicator development. Report prepared for the Sarasota Bay Estuary Program (Technical Report Number 2017SBEP04). Sarasota, FL.

Krebs, Justin M., Brame, Adam B. and McIvor Carole C. 2007. Altered mangrove wetlands as habitat for estuarine nekton: are dredged channels and tidal creeks equivalent? Bulletin of Marine Science 80: 839-861.

Krebs, J. M., E. B. Peebles, M. P. Weinstein and R.G. McConnell. 2010 Revisiting and updating our knowledge on the science of Tampa Bay's tidal tributaries. In: S.T. Cooper (ed.). Proceedings, Tampa Bay Area Scientific Information Symposium, BASIS 5: 20-23 October 2009. St. Petersburg, FL, pp. 387-395.

Ley, J.A., and H.J. Rolls. 2018. Using otolith microchemistry to assess nursery habitat contribution and function at a fine spatial scale. Marine Ecology Progress Series 606: 151-173. https://doi.org/ 10.3354/meps 12765 .

Littell, R.C., G.A. Milliken, W.W. Stroup, and R.D. Wolfinger. 2006. SAS System for Mixed Models. Cary, N.C.: SAS Institute Inc.

Lowndes, J.S.S., B.D. Best, C. Scarborough, J.C. Afflerbach, M.R. Frazier, C.C. O'Hara, N. Jiang, and B.S. Halpern. 2017. Our path to better science in less time using open data science tools. Nature Ecology \& Evolution. 1: 1-7. https://doi.org/10.1038/ s41559-017-0160.

Malkin, E., D. Hollander, and E. Peebles. 2010. Using estuarine fish stable nitrogen isotopes to pinpoint land cover nutrient origins. In: S.T. Cooper (ed.). Proceedings, Tampa Bay Area Scientific
Information Symposium, BASIS 5: 20-23 October 2009. St. Petersburg, FL. pp. 347-354.

Mallin, Michael A., E Cartier Esham, Kathleen E. Williams, and Janice E. Neerhoof. 1999. Tidal stage variability of fecal coliform and chlorophyll a concentrations in coastal creeks. Marine Pollution Bulletin 38 (5): 414-422.

Mallin, M.A., and A.J. Lewitus. 2004. The importance of tidal creeks. Journal of Experimental Marine Biology and Ecology 298: 145-149.

Mallin, Michael A., Douglas C. Parsons, Virginia L. Johnson, Matthew R. McIver, and Heather A. Covan. 2004. Nutrient limitation and algal blooms in urbanizing tidal creeks. Journal of Experimental Marine Biology and Ecology. 298: 211-231.

McKay, L., T. Bondelid, T. Dewald, J. Johnston, R. Moore, and A. Rhea. 2012. NHD-Plus version 2: user guide. https://pubs.er.usgs. gov/publication/ofr20191096. Accessed 01 November 2020.

McPherson, Benjamin F. and K. M. Hammett 1991. Tidal rivers of Florida. In: The rivers of Florida, R. J. Livingston (Editor). Springer Verlag. New York.

National Research Council 2000. Clean coastal waters: understanding and reducing the effects of nutrient pollution. Washington, DC: The National Academies Press. https://doi.org/10.17226/9812. Accessed 08 December 2020.

Nixon, S.W. 1995. Coastal marine eutrophication: A definition, social causes, and future concerns. Ophelia 41 (1): 199-219. https://doi. org/10.1080/00785236.1995.10422044.

Novak, Rachael, Kennen, J.G., Abele, R.W., Baschon, C.F., Carlisle, D.M., Dlugolecki, Laura, Eignor, D.M., Flotemersch, J.E., Ford, Peter, Fowler, Jamie, Galer, Rose, Gordon, L.P., Hansen, S.E., Herbold, Bruce, Johnson, T.E., Johnston, J.M., Konrad, C.P., Leamond, Beth, and Seelbach, P.W, 2016, Final EPA-USGS technical report: protecting aquatic life from effects of hydrologic alteration: U.S. Geological Survey Scientific Investigations Report 2016-5164, U.S. Environmental Protection Agency EPA Report 822-R-156-007, 156 p. http://pubs.usgs.gov/sir/2015/5160/ and http://www2.epa.gov/wqc/aquatic life-ambient-water qualitycriteria. Accessed 08 December 2020.

Paulic, M. J. Hand and L. Lord 1996. Water quality assessment for the State of Florida: section 305[B]. Florida Department of Environmental Protection. December 1996. http://www.hillsborough. wateratlas.usf.edu/upload/documents/1996\%20Water-Quality\% 20 Assessment $\% 20$ for $\% 20$ the $\% 20$ Sta te $\% 20$ of $\% 20$ Florida $\%$ 20Section\%20305(b)\%20Main\%20Report.pdf. Accessed 15 June 2017.

Peebles, E. 2015. Zooplankton and hyperbenthos as community metrics for the trophic state of tidal creeks. Tampa Bay Estuary Program Technical Publication: 03-15. 31pp.

Pinkney, J., R. Papa, and R. Zingmark. 1994. Comparison of high performance liquid chromatographic, spectrophotometric, and fluorometric methods for determining chlorophyll a concentrations in estuarine sediments. Journal of Microbiological Methods 19: 59-66.

R Core Team (2020). R: a language and environment for statistical computing, v3.6.3. R Foundation for Statistical Computing, Vienna, Austria. URL http://www.R-project.org/.

Rokach, L.ior and Oded Maimon. 2008. Data mining with decision trees: theory and applications. Series in Machine perception artificial intelligence. Vol 69. World Scientific Publishing Co. Singapore.

Rousseeuw, Peter J., and Annick M. Leroy. 2003. Robust Regression and Outlier Detection, 354. New York: Wiley and Sons.

Sanger, D., A. Blair, G. DiDonato, T. Washburn, S. Jones, G. Riekerk, E. Wirth, J. Stewart, D. White, L. Vandiver, and A.F. Holland. 2015. Impacts of Coastal Development on the Ecology of Tidal Creek Ecosystems of the US Southeast including Consequences to Humans. Estuaries and Coasts 38 (Suppl 1): 49-66. https://doi. org/10.1007/s12237-013-9635-y. 
SAS Institute. 2019. The SAS system for Windows. Release 9.4. SAS Institute, Cary, NC.

Sherwood, E.T. 2008.Tampa Bay Tidal Tributary Habitat Initiative Project: final report and management recommendations. Tampa Bay Estuary Program Technical Report. 02-08: 78 pp.

Sherwood, E.T. 2010. Results and management recommendations from the 2006 Tampa Bay Tidal Tributaries Habitat Initiative. In: S.T. Cooper (ed.). Proceedings, Tampa Bay Area Scientific Information Symposium, BASIS 5: 20-23 October 2009. St. Petersburg, FL, pp. 355-373.

Strahler, A.N. 1952. Hypsometric (area-altitude) analysis of erosional topology. Geological Society of America Bulletin 63 (11): 1117-1142. https://doi.org/10.1130/0016-7606(1952)63[1117: HAAOET]2.0.CO;2.

U.S. Department of Agriculture, Natural Resources Conservation Service. National Soil Survey Handbook. n.d. title 430-VI. http://www.nrcs.usda.gov/wps/portal/nrcs/detail/soils/ref/?cid= nrcs142p2_054242 Accessed 08 September 2019.
Vincente - Serrano, S. M., S. Begueria, and J. I. Lopez-Moreno. 2010. A multiscaler drought index sensitive to global warming: The Standardized Precipitation Evaporation Index. Journal of Climate. V23: 1696-1718.

Whitney, David E., and W Marshall Darley. 1979. A method for the determination of chlorophyll $a$ on samples containing degradation products. Limnology. Oceanography. 24 (1): 1983-1986.

Wickham, J., Stehman, S. V., Neale, A. C., Mehaffey, M. 2020. Accuracy assessment of NLCD 2011 percent impervious cover for selected USA metropolitan areas: International Journal of Applied Earth Observation and Geoinformation. 84. https://doi.org/10. 1016/j.jag.2019.101955.

Wolanski, Eric. 2007. Estuarine ecohydrology. Amsterdam: Elsevier.

Yeager, L.A., J.M. Krebs, C.C. McIvor, and A.B. Brame. 2007. Juvenile blue crab abundances in natural and man-made tidal channels in mangrove habitat, Tampa Bay, Florida (USA). Bulletin of Marine Science 80: 555-565. 